\title{
The Role of Steroids on Brain Function
}

\section{Amin Nico-khesal ${ }^{1}$, Haniyeh Bakhtiari' ${ }^{1}$, Afsaneh Akhzary ${ }^{1}$, Khadijeh Heidar-beigi², Parastoo Barati Dowom², Marzieh Darvishi' ${ }^{2,}$}

${ }^{1}$ Faculty of Medicine, Ilam Universityof Medical Sciences, Ilam, Iran ${ }^{2}$ Shefa Neuroscience Research Center, Khatam Alanbia Hospital, Tehran, Iran ${ }^{3}$ Department of Anatomy, Faculty of Medicine, Ilam University of Medical Sciences, Ilam, Iran

\section{ABSTRACT}

Introduction: Steroids have different effects on brain across the lifespan, pregnancy and aging. These will influence on the areas of the brain that play a role in reproduction, such as the hippocampus, the putamen, and the midbrain raphe. Steroid hormones cross the blood-brain barrier and easily reach the neuronal tissue. These hormones are involved in female menstrual cycle, pregnancy and embryogenesis. Steroids are produced in the ovaries, the adrenal glands, and during pregnancy in the placenta and stored in fat tissue. In recent years, extensive studies have been conducted on the role of steroids on the nervous system activities. After central nervous system (CNS) injury, steroids regenerate neuronal and axonal damage. Steroids influence neuronal activity and are important for normal brain functions. These hormones act via receptor-ligand binding and phosphorylation mechanisms in the brain. Conclusion: Steroid receptors are collected in neural cells of the hypothalamus and the hippocampus. This can explain the relation of steroids with sexual behavior in these brain regions. Despite intensive studies on reproductive behaviors set by estrogen and progesterone, a lot in relation to its effect has remained undiscovered. Use of steroids and modulation of their receptors in hormone therapy have been considered to maintain healthy nerve function during menopause.

\section{Key words:}

1. Progesterone

2. Estradiol

3. Neurogenesis

\section{*Corresponding Author: Marzieh Darvishi}

E-mail: Marzidarvish@yahoo.com

doi: 10.18869/acadpub.shefa.5.1.58 


\section{نقش استروئيدها بر عملكرد مغز}

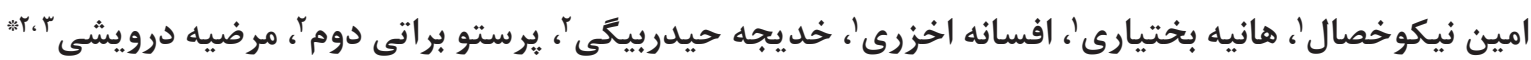

'دانشكده يزشكى، دانشعاه علوم يزشكى ايلام، ايلام، ايران

rمركز تحقيقات علوم اعصاب شفا، بيمارستان خاتم الانبياء، تهران، ايران

"آروه آناتومى، دانشكده يزشكى، دانشكاه علوم يزشكى ايلام، ايلام، ايران

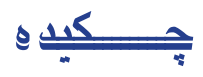

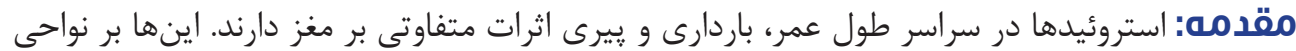

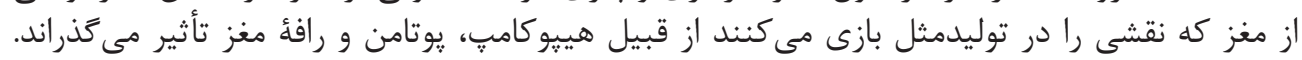

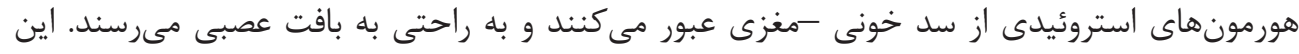

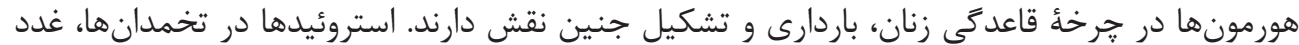

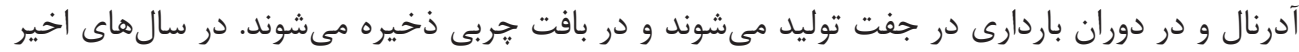

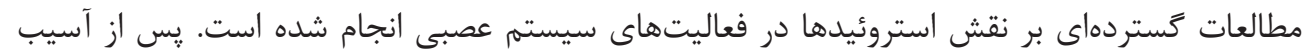

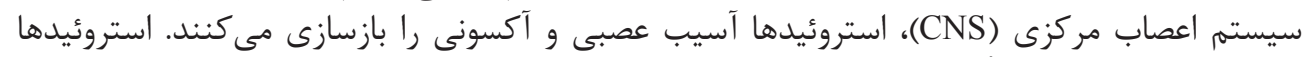

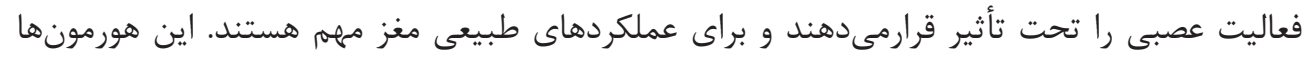

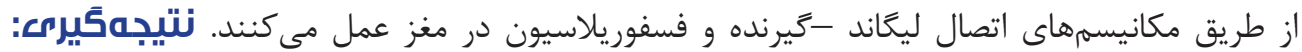

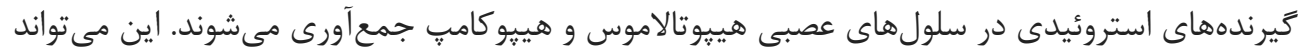

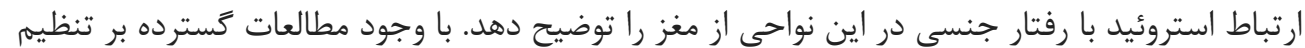

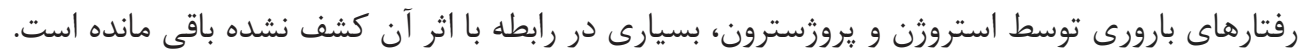

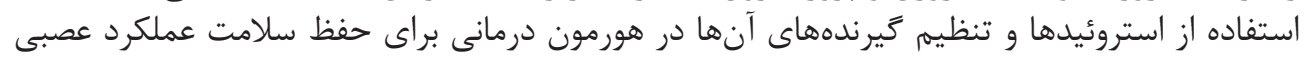

كليد وازهها:

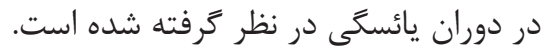

ا

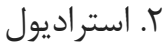

س. نورونزايى الستي

" نويسنده مسئول: مرضيه درويشى آدرس الكترونيكى: Marzidarvish@yahoo.com 


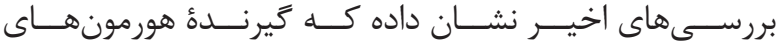

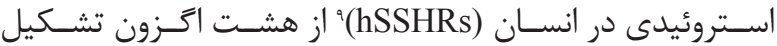

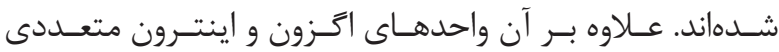

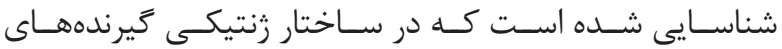

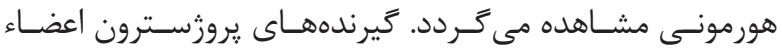

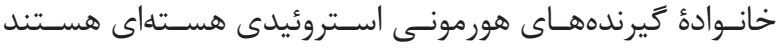

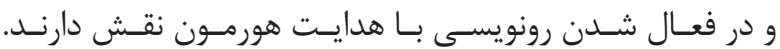

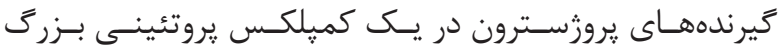

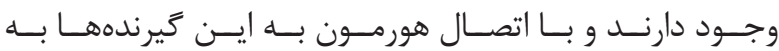

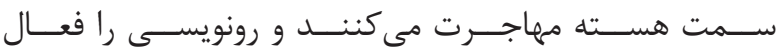

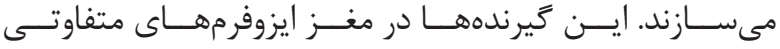

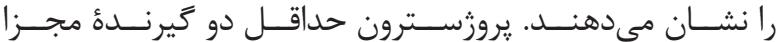

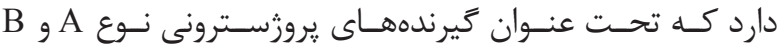

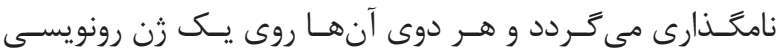

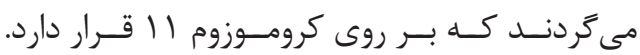

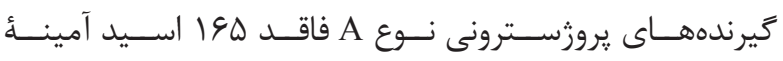

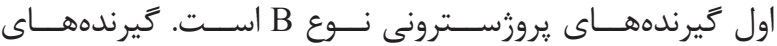

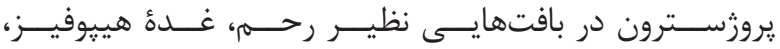

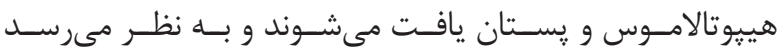

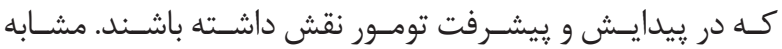

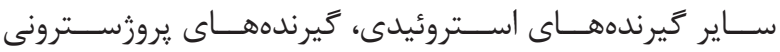

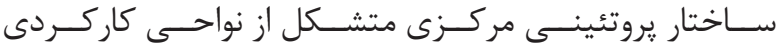

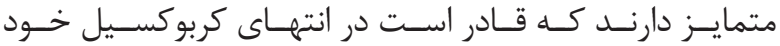

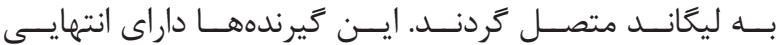

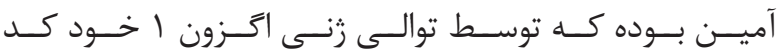

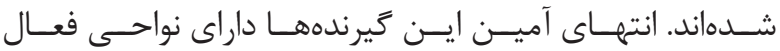

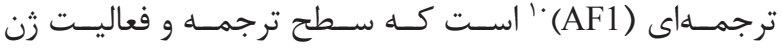

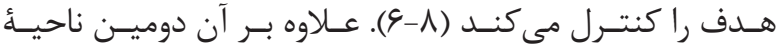

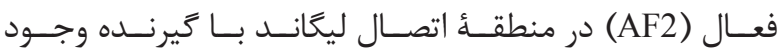

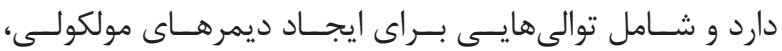

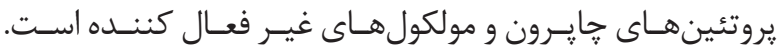

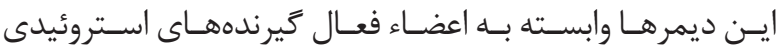

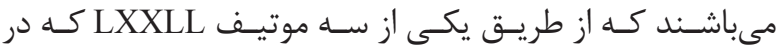

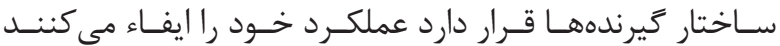

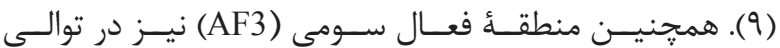

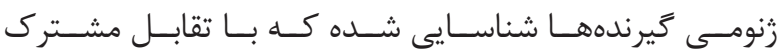

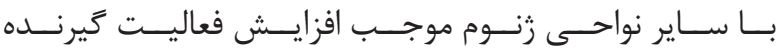

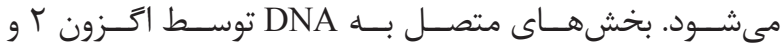

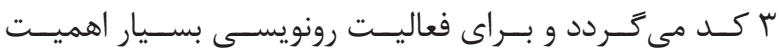

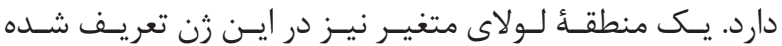

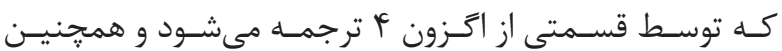

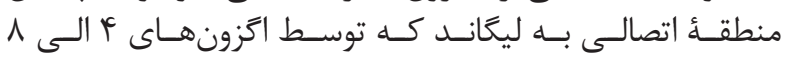

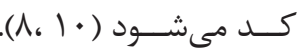

\footnotetext{
${ }^{1}$ Blood-brain barrier

${ }^{2}$ Pregnenolone

${ }^{3}$ Central nervous system

${ }^{4}$ Limbic system

${ }^{5} \beta 17$ - estradiol
}

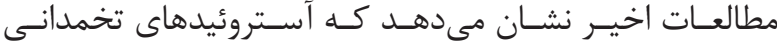

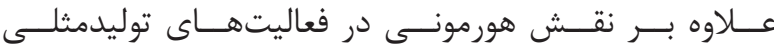

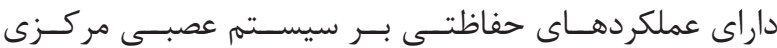

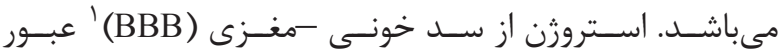

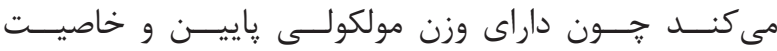

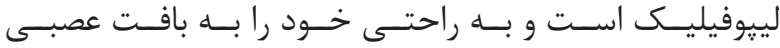

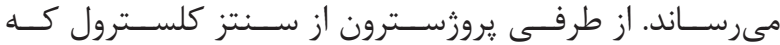

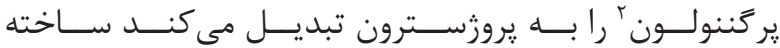

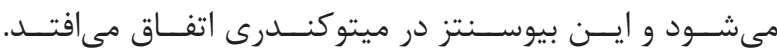

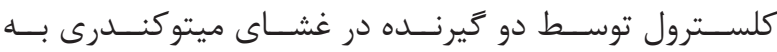

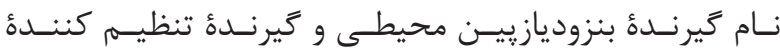

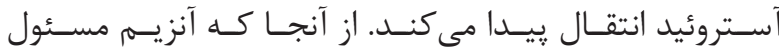

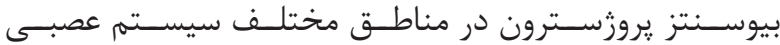

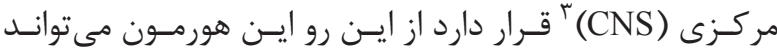

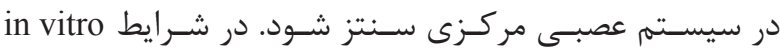

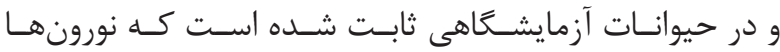

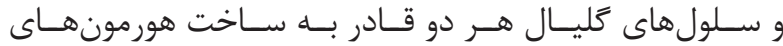

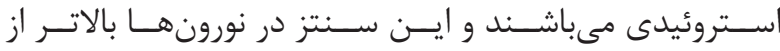

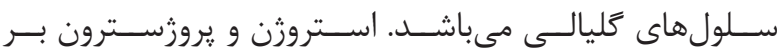

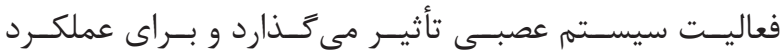

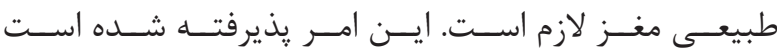

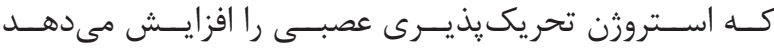

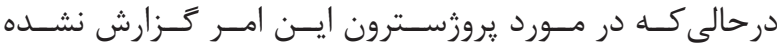

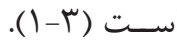

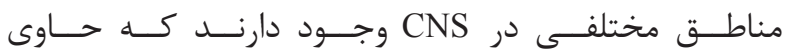

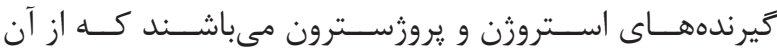

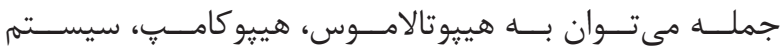

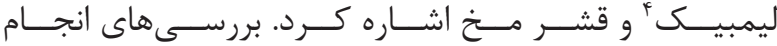

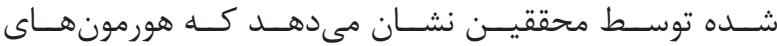

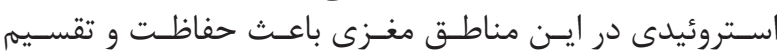

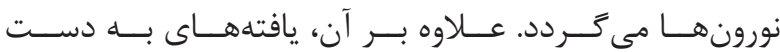

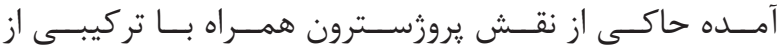

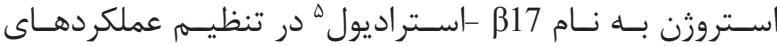

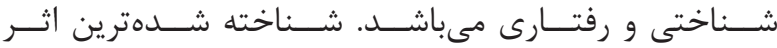

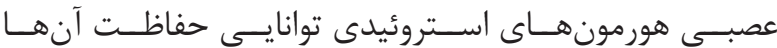

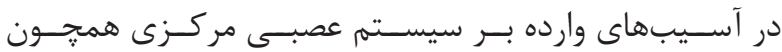

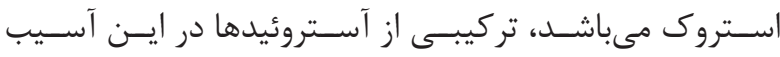

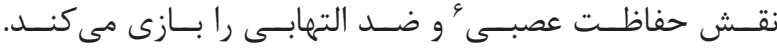

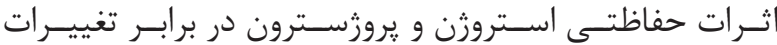

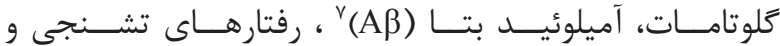

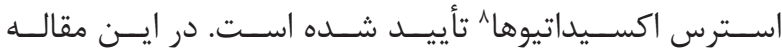

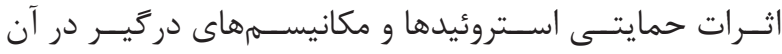

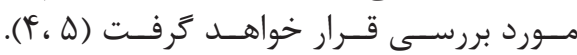

\footnotetext{
${ }^{6}$ Neuroprotection

${ }^{7}$ Amyloid beta

${ }^{8}$ Oxidative stress

${ }^{9}$ Human sex steroid hormone receptors

${ }^{10} 1$ Activation function
} 


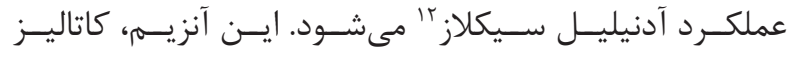

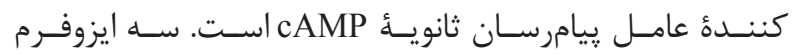

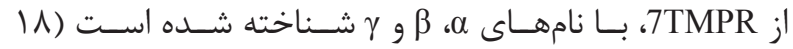

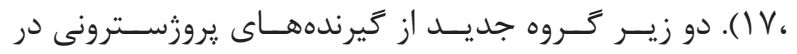

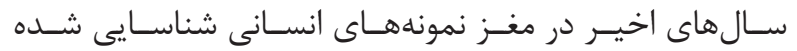

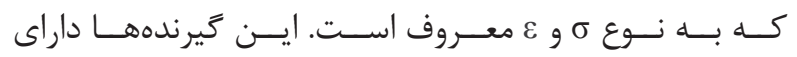

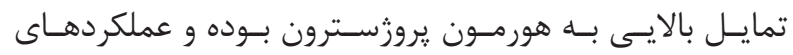

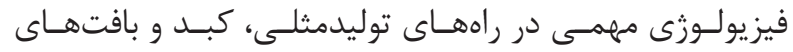

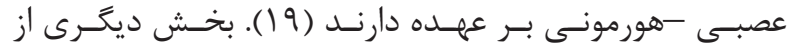

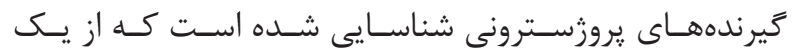

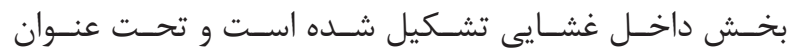

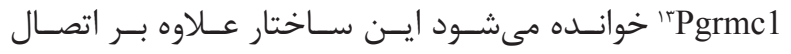

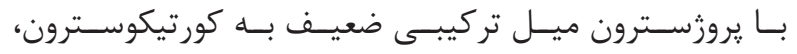

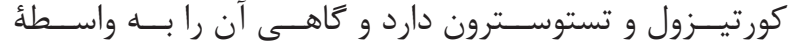

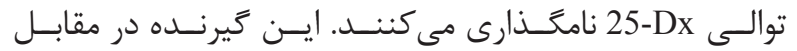

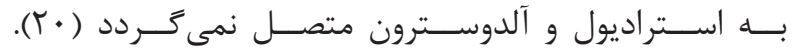

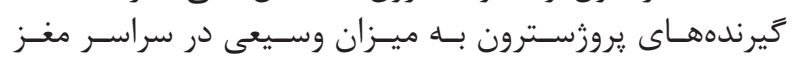

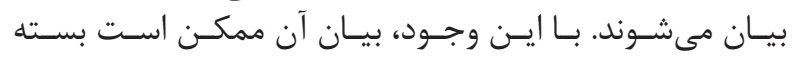

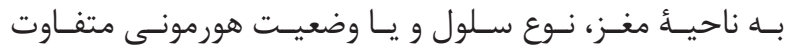

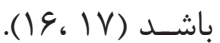

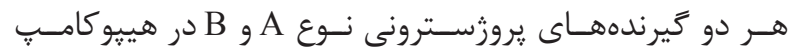

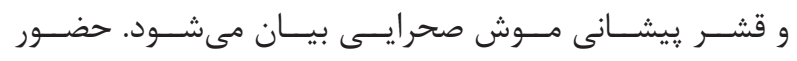

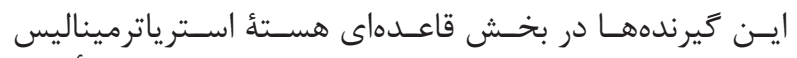

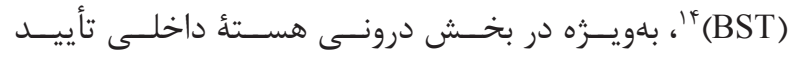

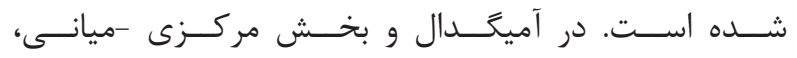

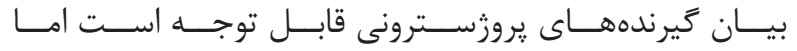

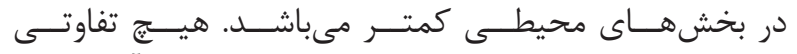

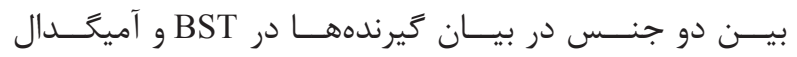

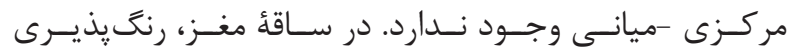

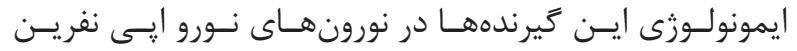

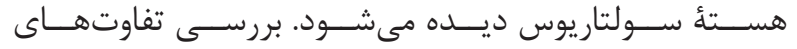

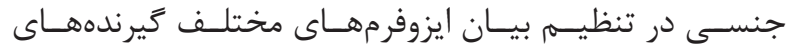

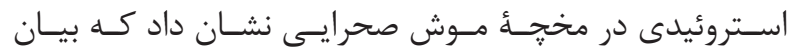

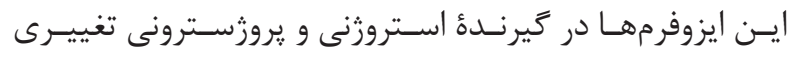

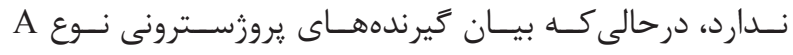

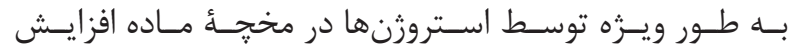

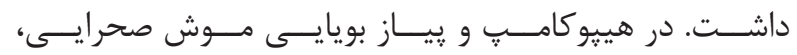

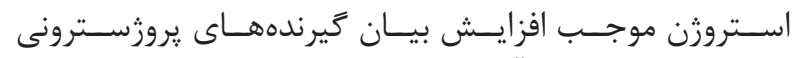

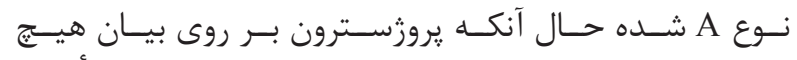

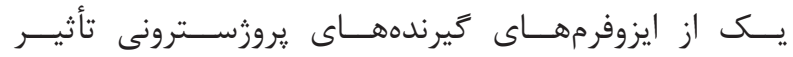

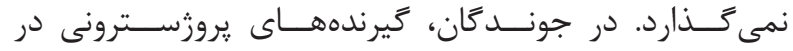

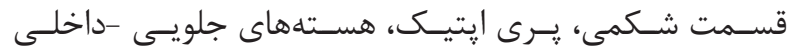

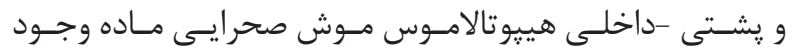

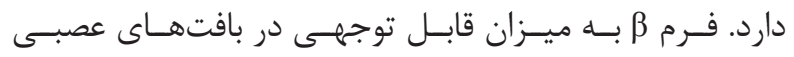

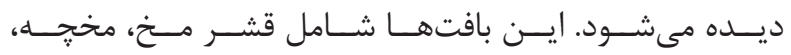

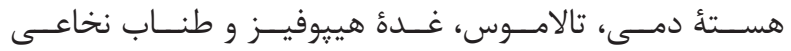

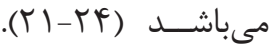

${ }^{11} 7$ Trans membran protien receptor

${ }^{12}$ Adenylyl cyclase

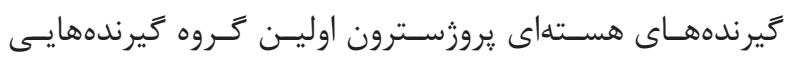

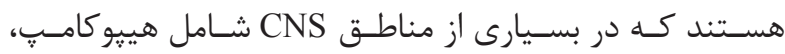

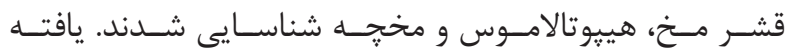

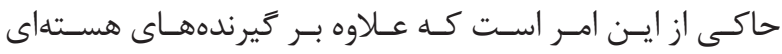

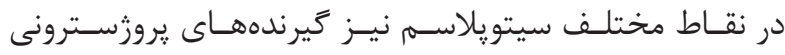

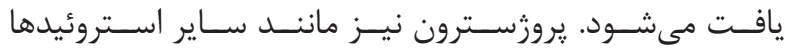

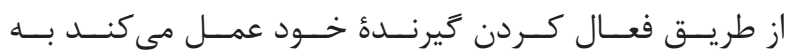

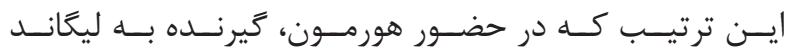

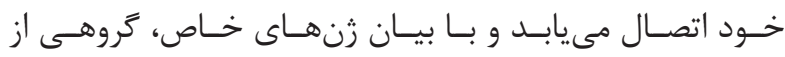

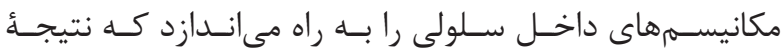

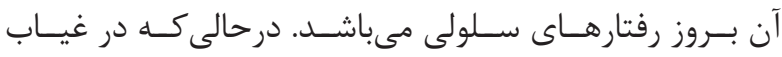

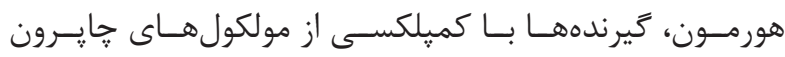

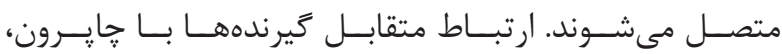

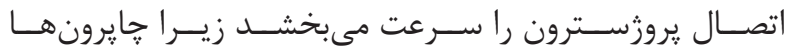

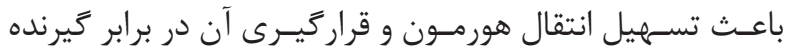

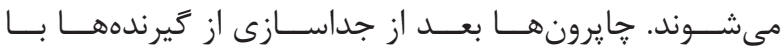

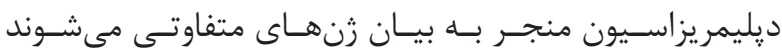

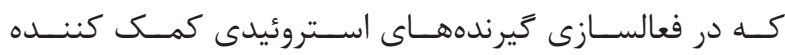

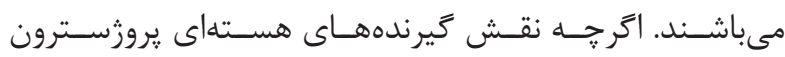

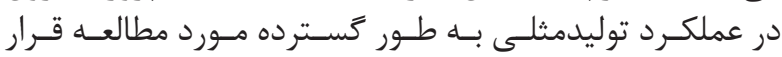

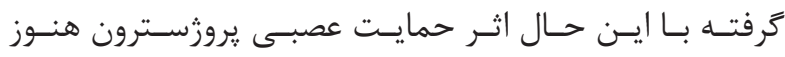

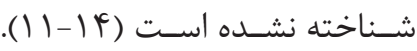

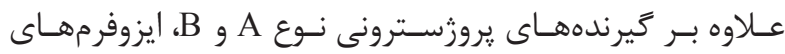

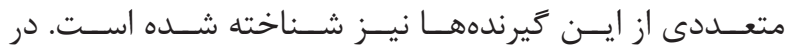

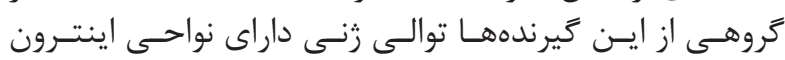

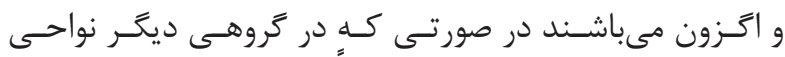

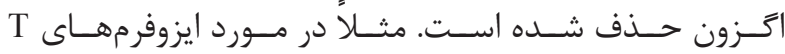

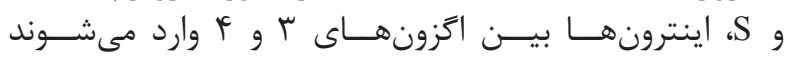

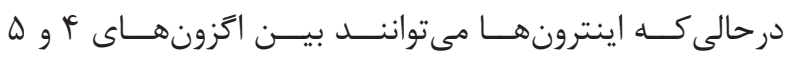

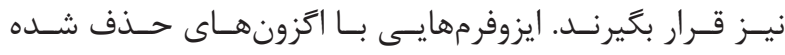

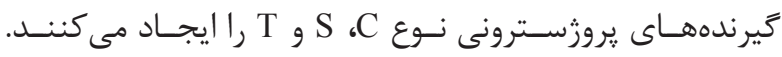

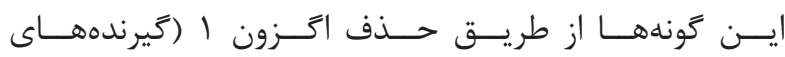

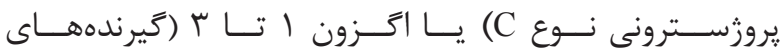

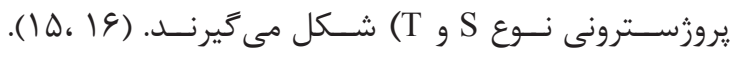

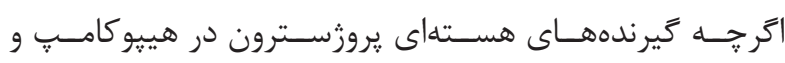

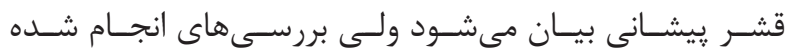

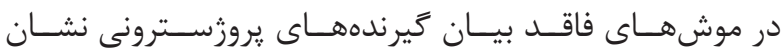

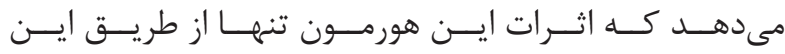

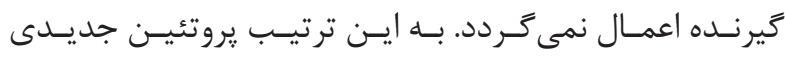

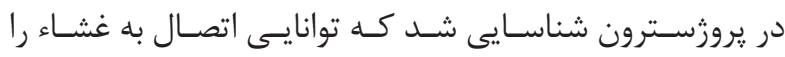

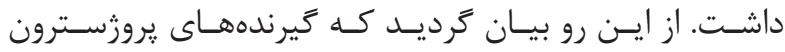

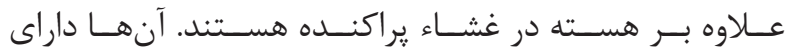

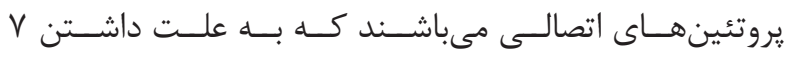

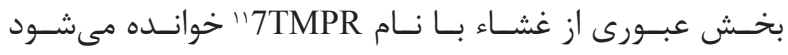

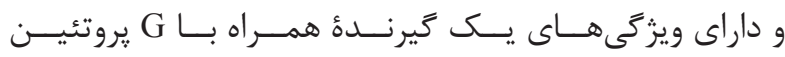

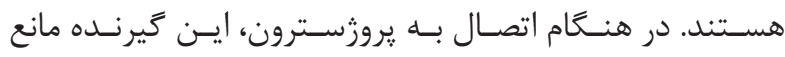

${ }^{13}$ Progesterone membrane receptor component

${ }^{14}$ Basal stria terminalis 


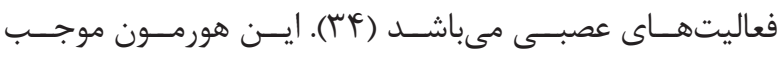

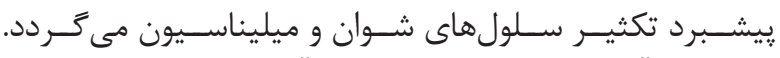

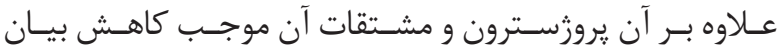

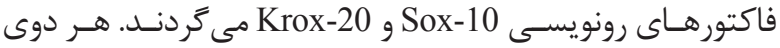

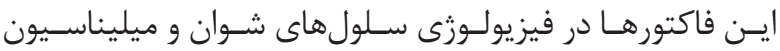

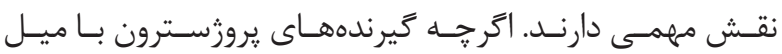

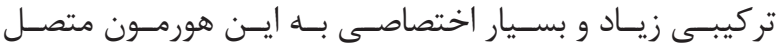

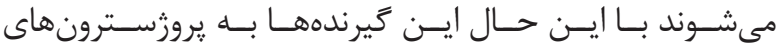

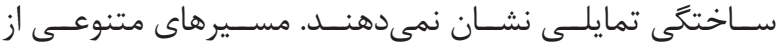

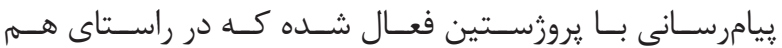

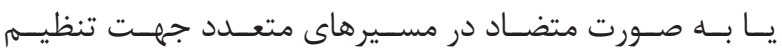

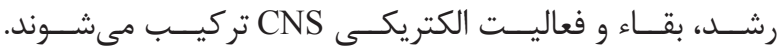

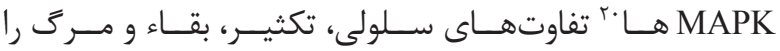

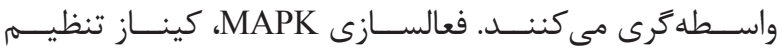

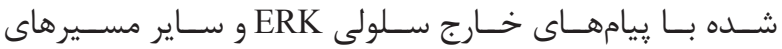

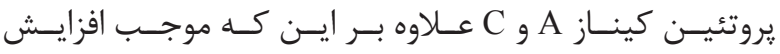

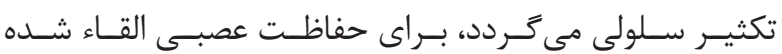

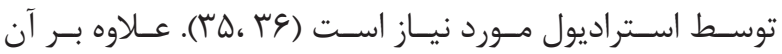

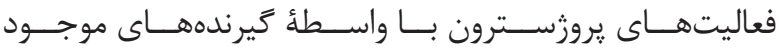

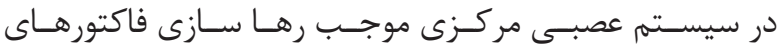

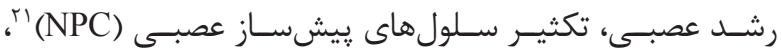

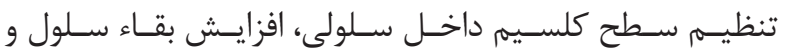

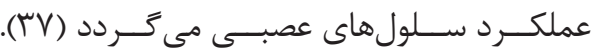

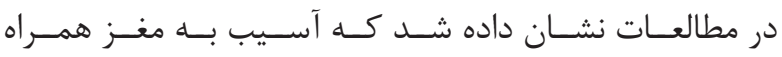

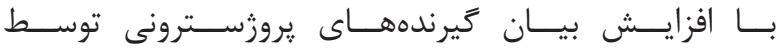

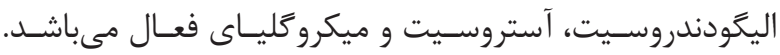

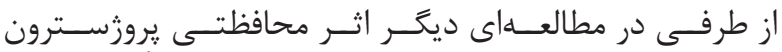

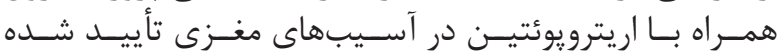

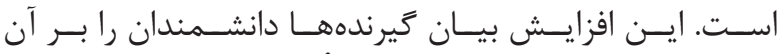

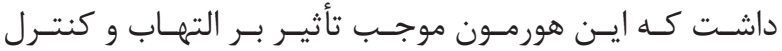

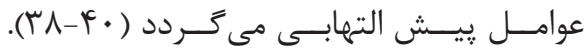

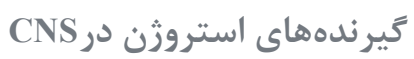

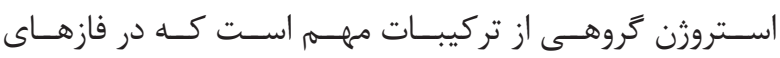

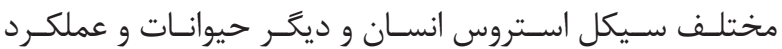

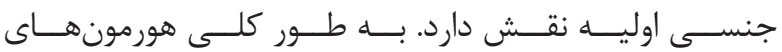

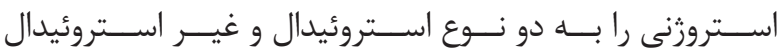

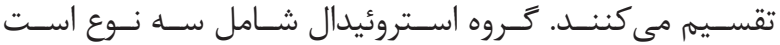

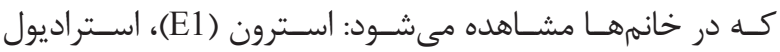

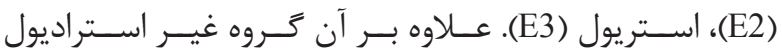

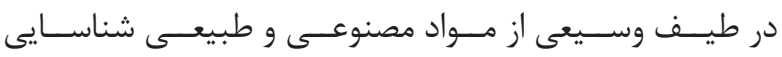

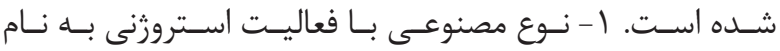

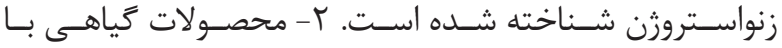

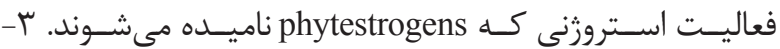

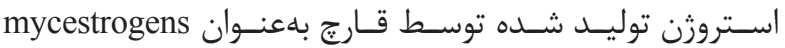

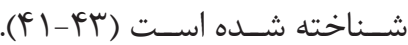

\footnotetext{
${ }^{15}$ Neurotransmitters

${ }^{16}$ Extracellular signal-related kinase

${ }^{17}$ Protein kinase A

${ }^{18}$ Dihydro progesterone
}

مكانيسم عملكردى يروزسترون در مغز

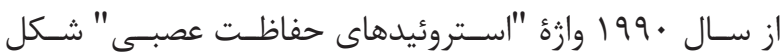

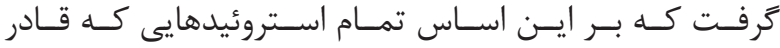

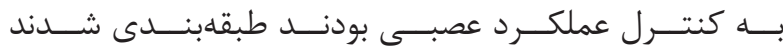

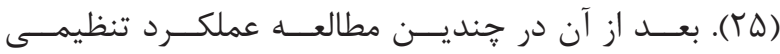

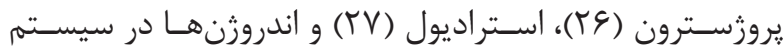

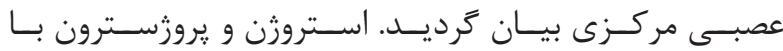

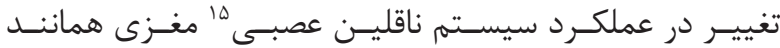

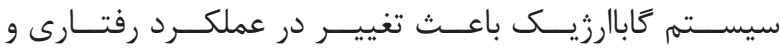

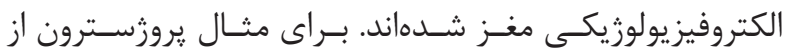

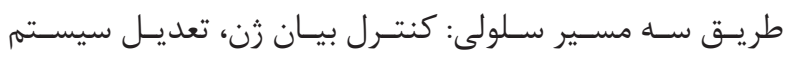

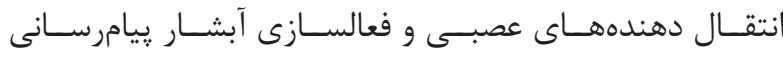

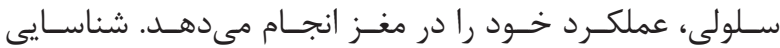

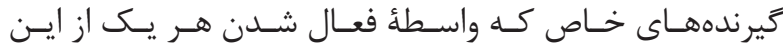

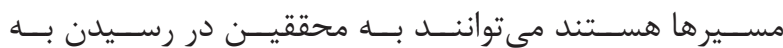

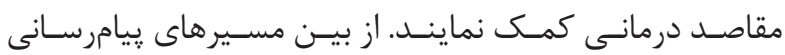

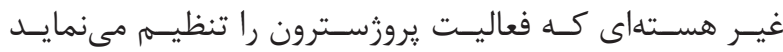

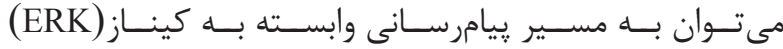

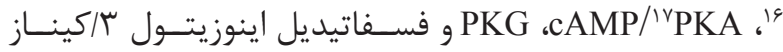

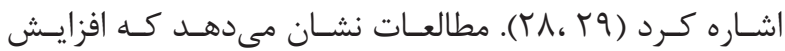

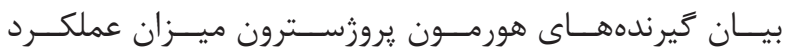

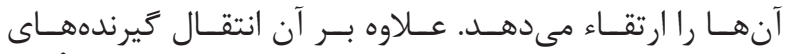

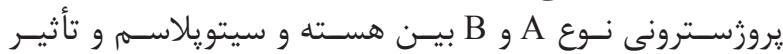

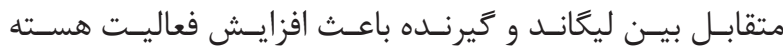

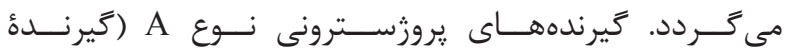

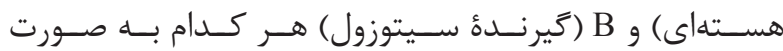

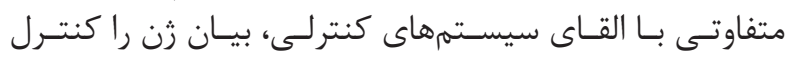

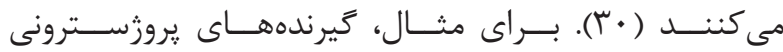

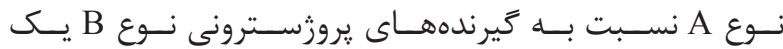

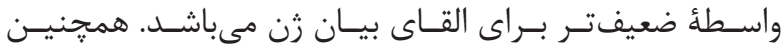

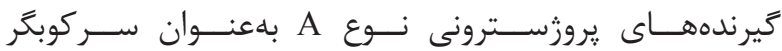

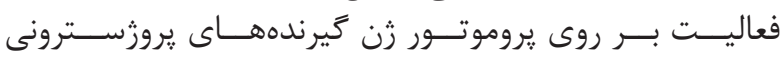

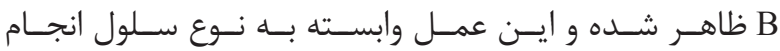

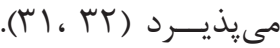

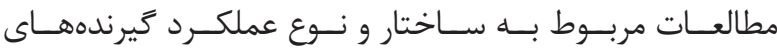

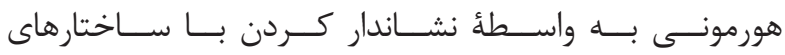

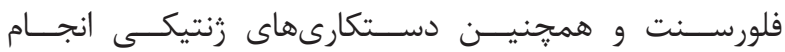

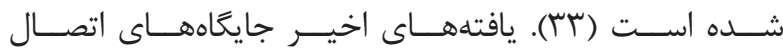

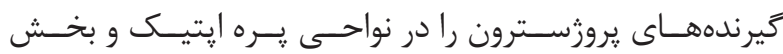

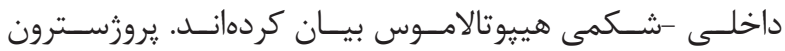

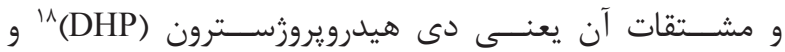

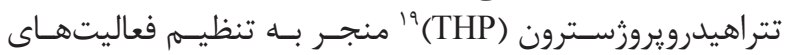

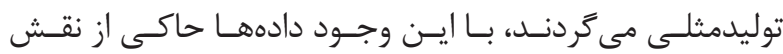

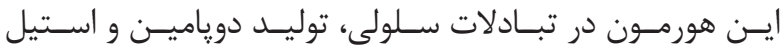

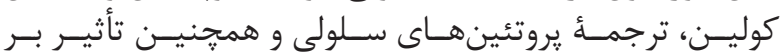

\footnotetext{
${ }^{19}$ Tetrahydro progesterone

${ }^{20}$ Mitogen-activated protein kinase

${ }^{21}$ Neural progenitor cell
} 


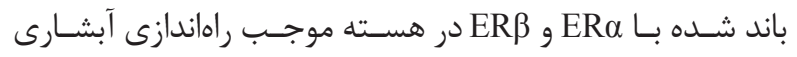

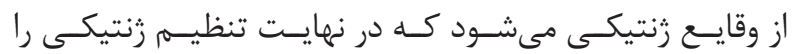

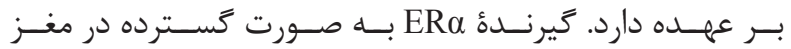

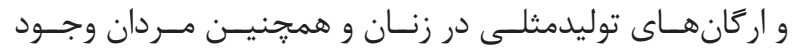

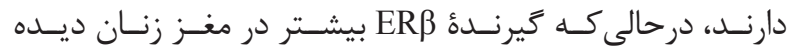

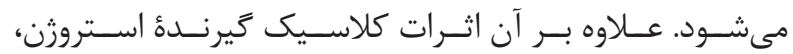

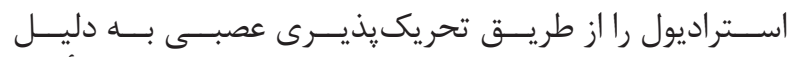

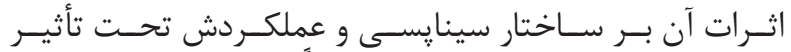

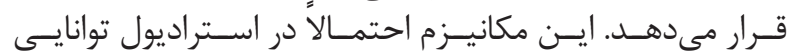

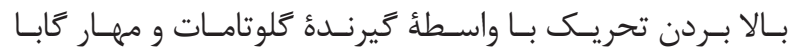

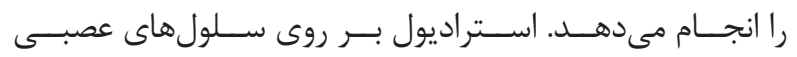

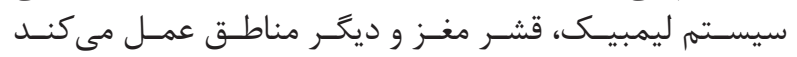

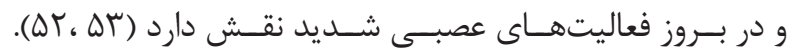

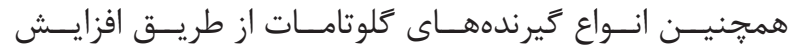

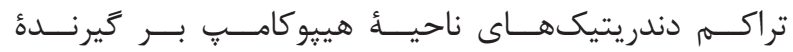

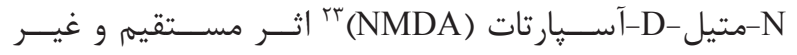

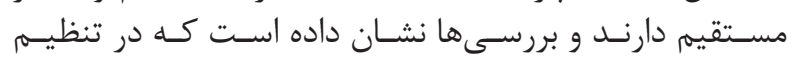

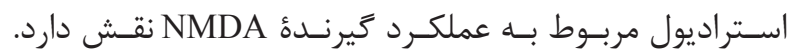

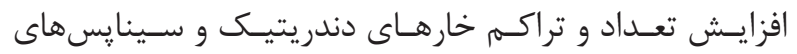

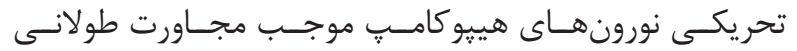

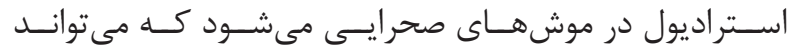

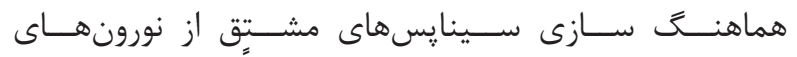

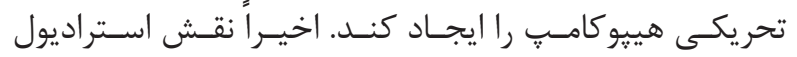

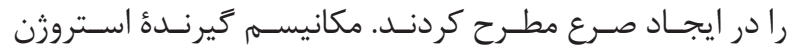

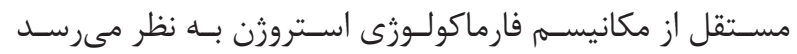

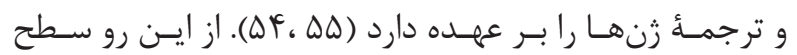

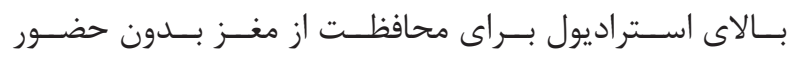

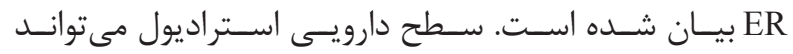

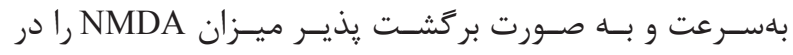

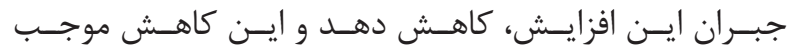

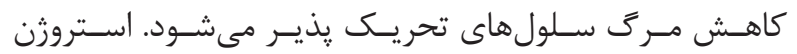

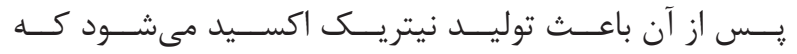

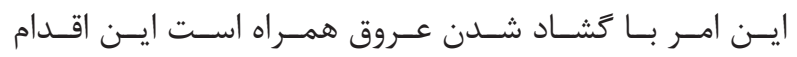

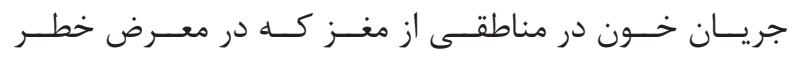

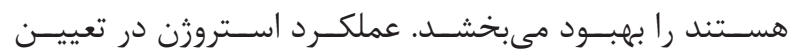

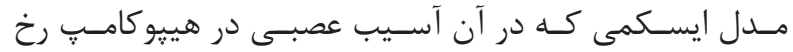

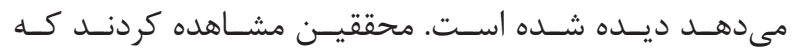

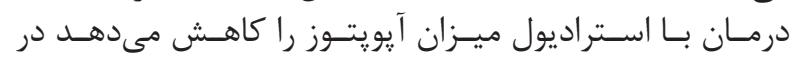

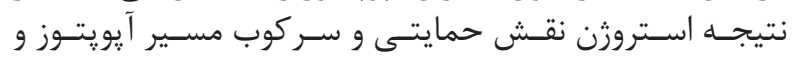

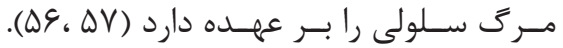

عملكردهاى متقابل استروثن و يروزسترون در CNS

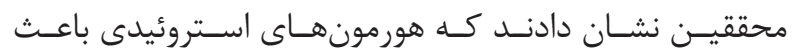

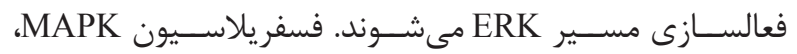

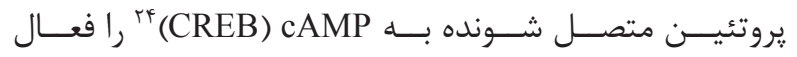

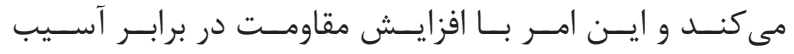

${ }^{22}$ Estrogen receptor

${ }^{23} \mathrm{~N}$ - methyl-D- aspartate

${ }^{24} \mathrm{cAMP}$ response element binding

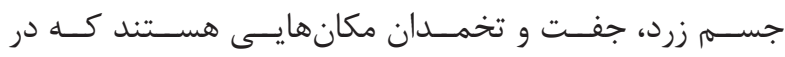

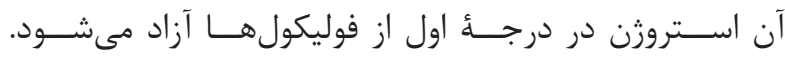

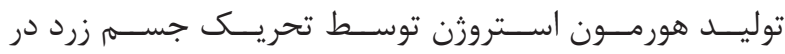

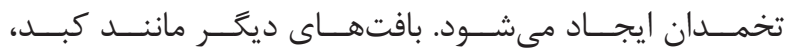

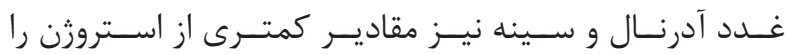

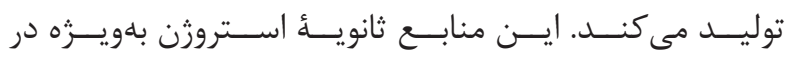

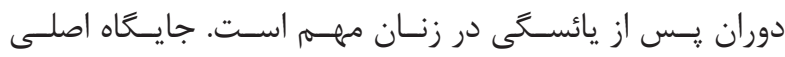

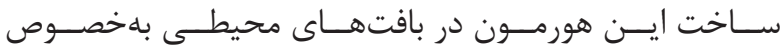

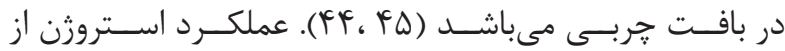

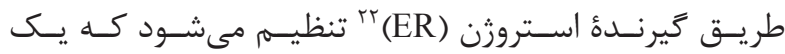

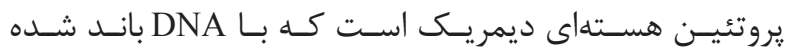

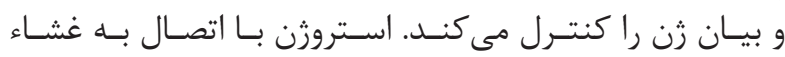

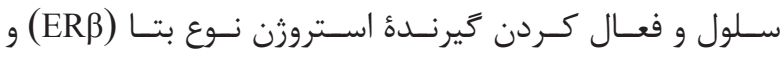

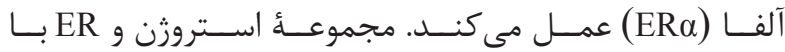

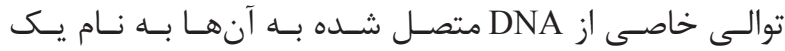

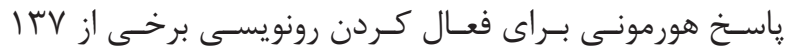

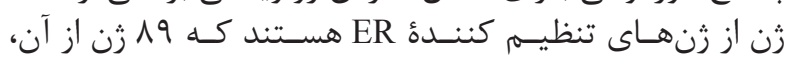

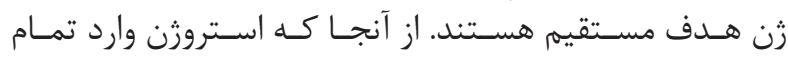

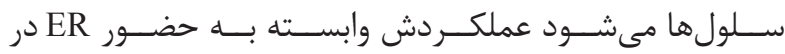

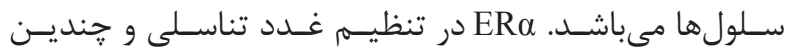

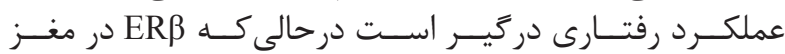

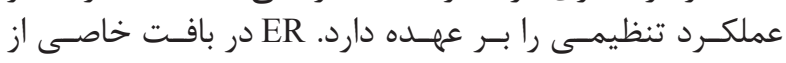

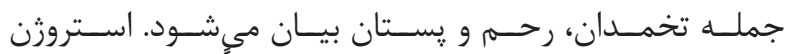

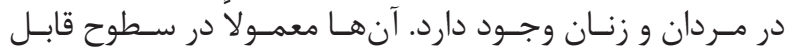

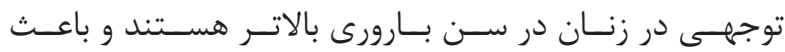

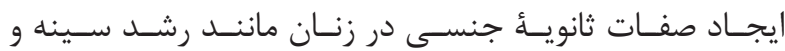

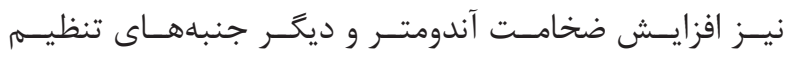

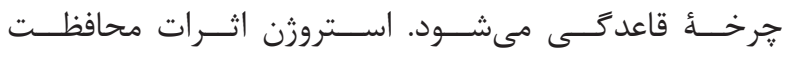

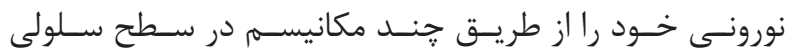

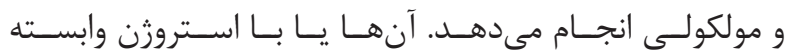

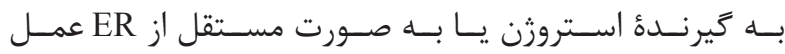

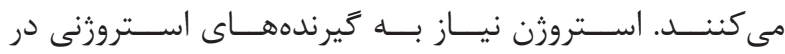

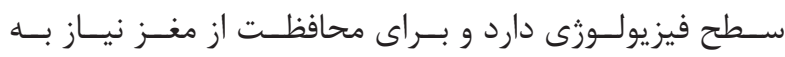

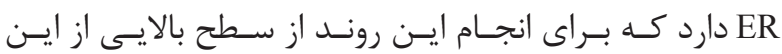

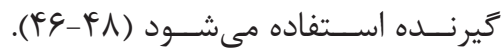

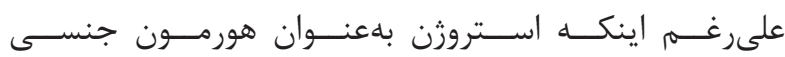

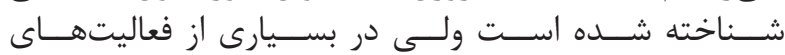

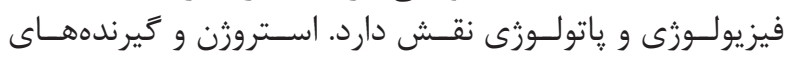

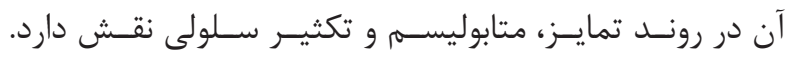

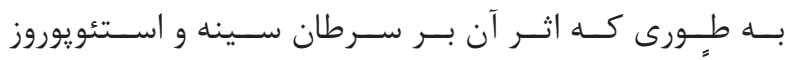

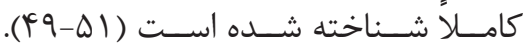

مكانيسم عملكردى استروڤن در مغز

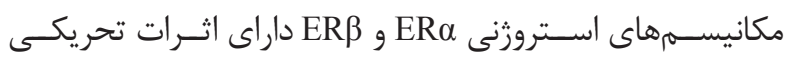

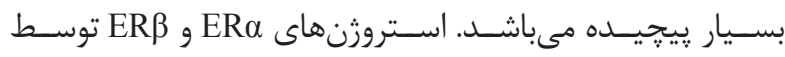

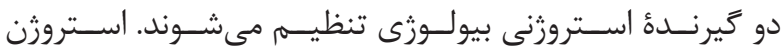




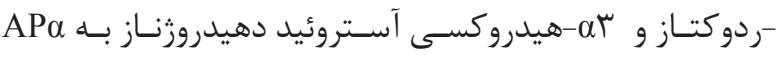

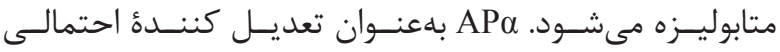

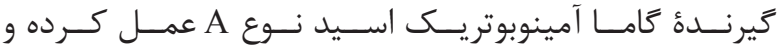

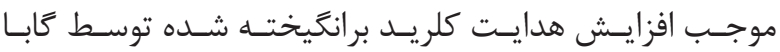

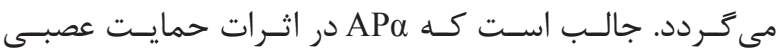

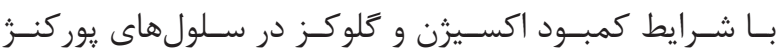

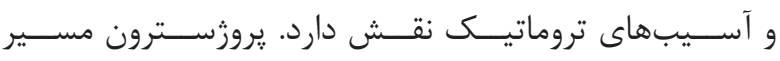

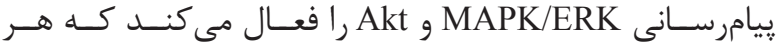

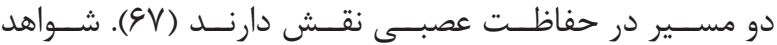

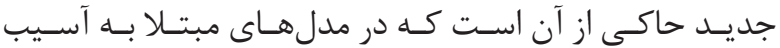

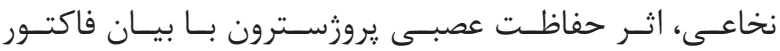

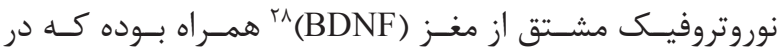

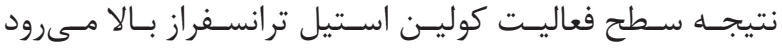

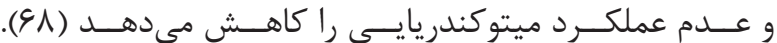

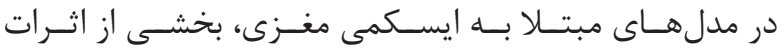

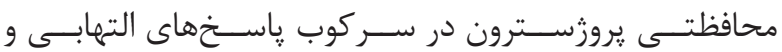

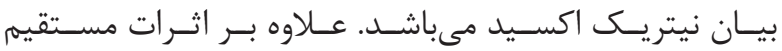

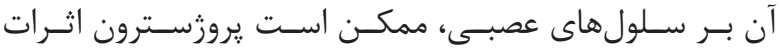

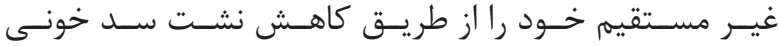

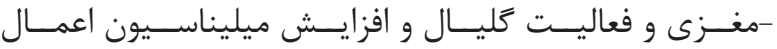

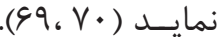

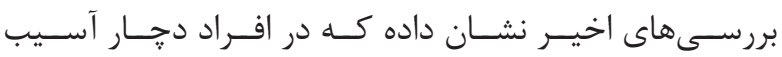

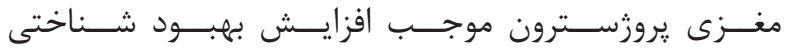

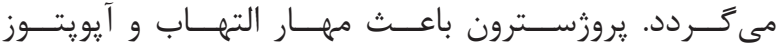

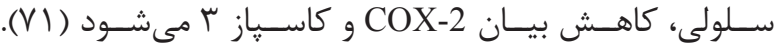

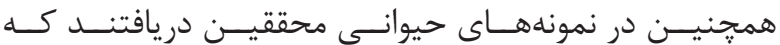

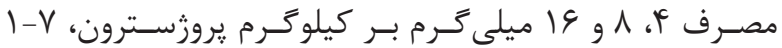

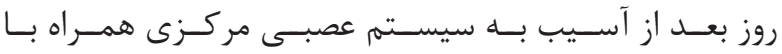

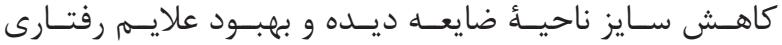

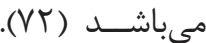

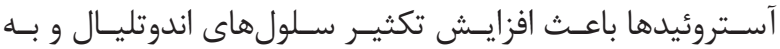

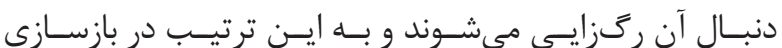

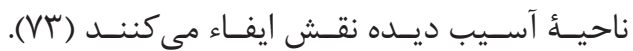

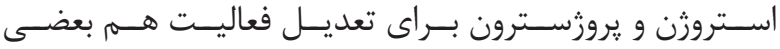

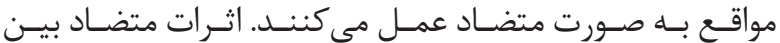

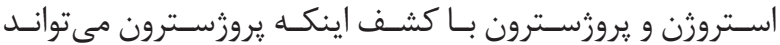

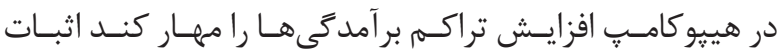

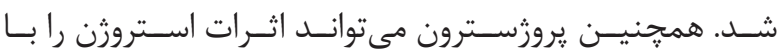

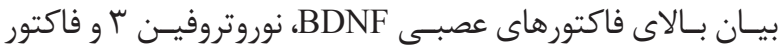

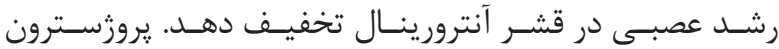

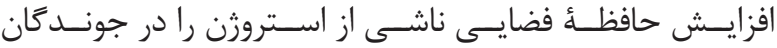

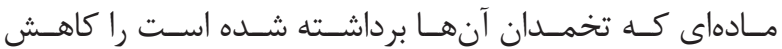

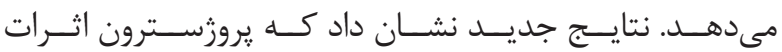

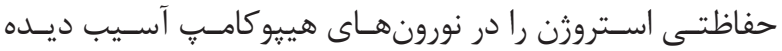

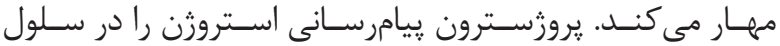

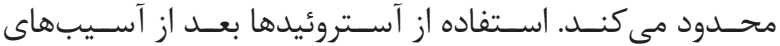

${ }^{25}$ B-cell lymphoma 2

${ }^{26}$ Protein kinase $\mathrm{B}$ (PKB), also known as Akt

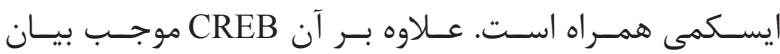

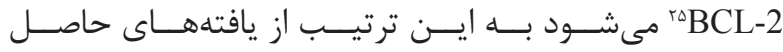

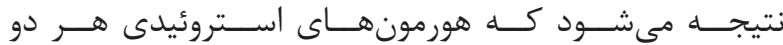

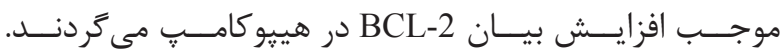

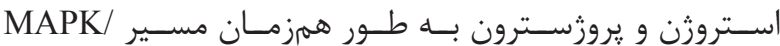

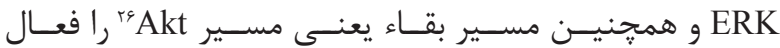

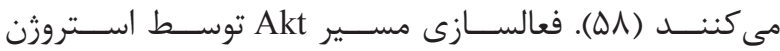

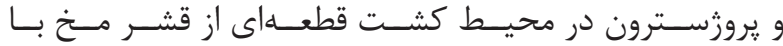

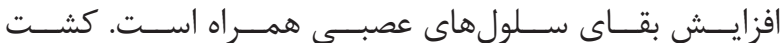

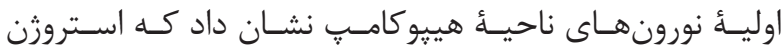

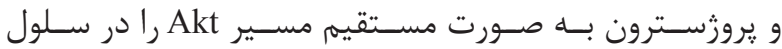

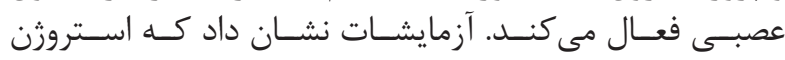

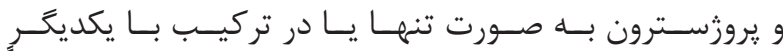

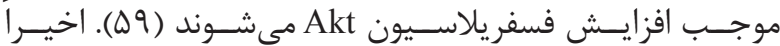

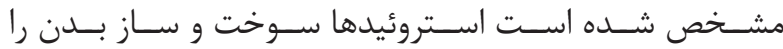

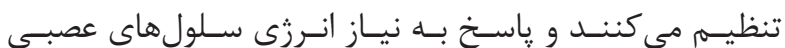

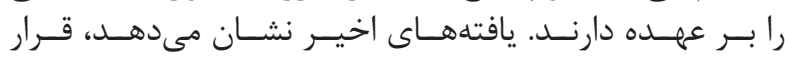

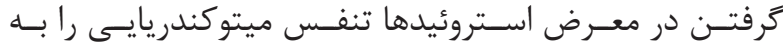

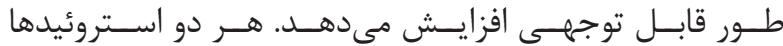

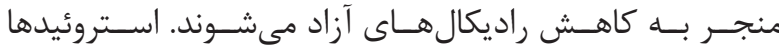

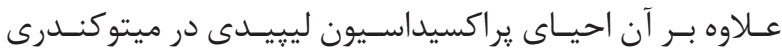

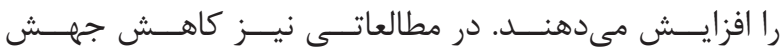

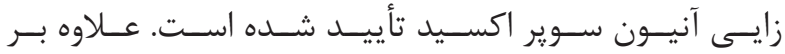

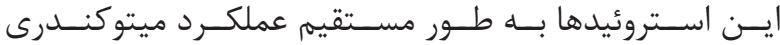

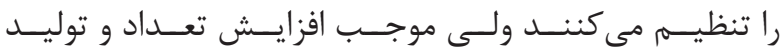

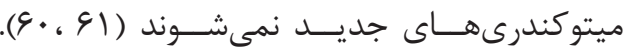

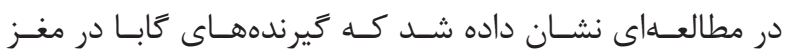

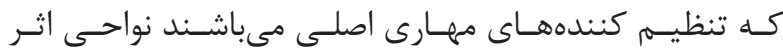

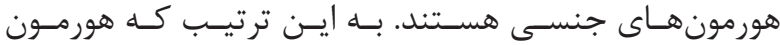

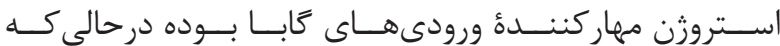

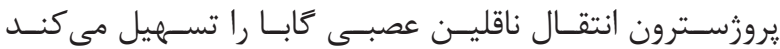

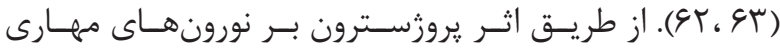

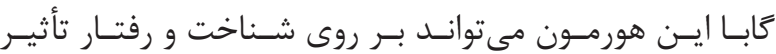

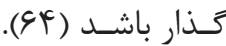

نقش حمايتى هور مونهاى استروئيدى در عملكرد CNS

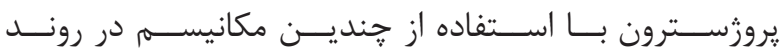

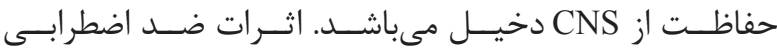

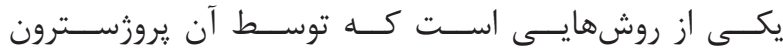

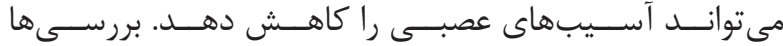

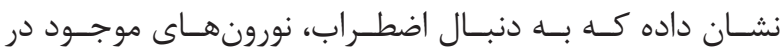

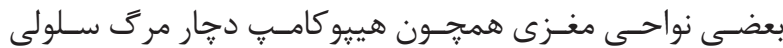

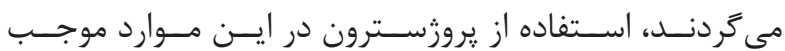

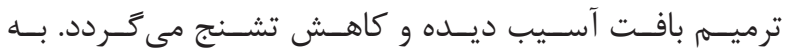

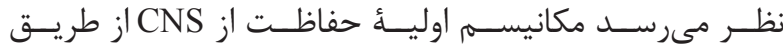

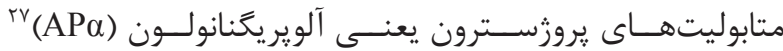

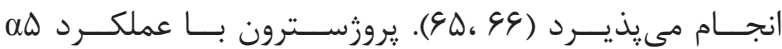

${ }^{27}$ Allopregnanolone

${ }^{28}$ Brain -derived neurotrophic factor 


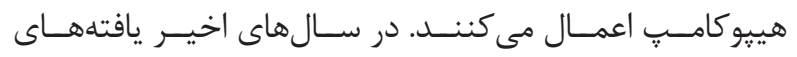

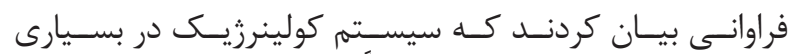

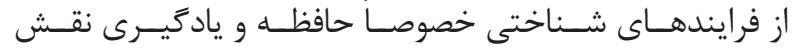

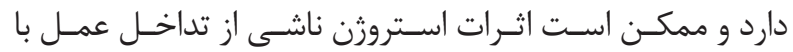

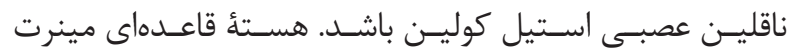

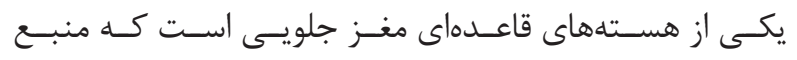

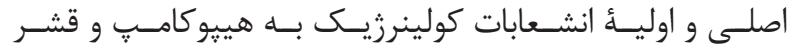

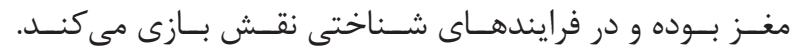

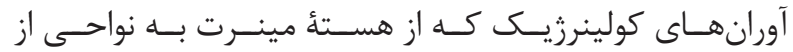

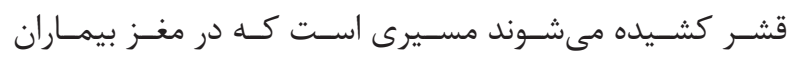

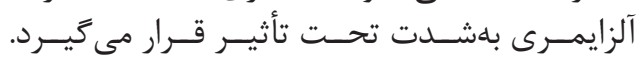

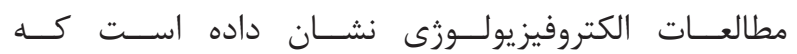

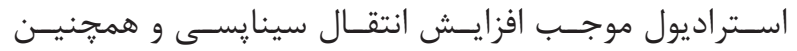

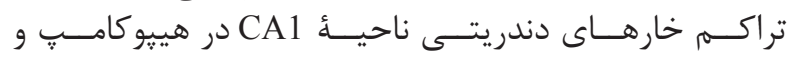

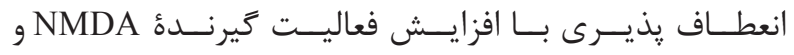

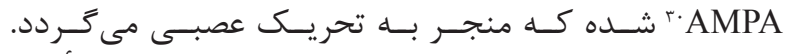

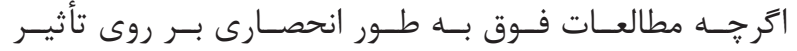

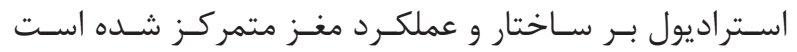

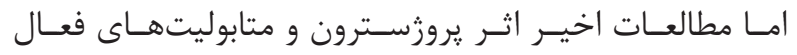

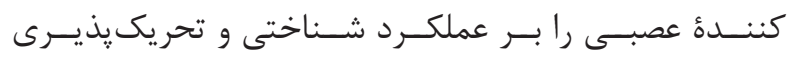

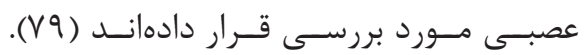

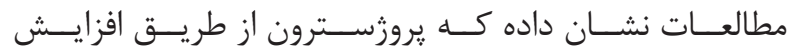

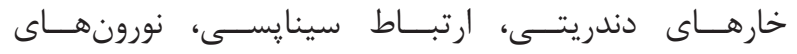

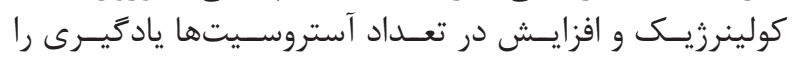

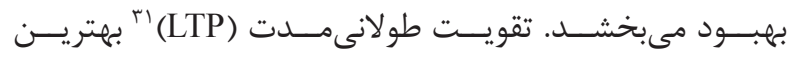

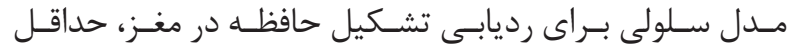

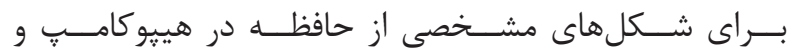

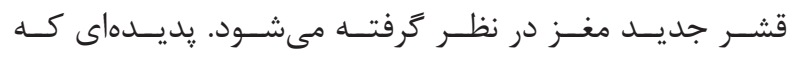

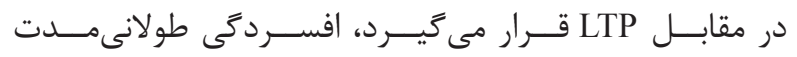
(LTD)

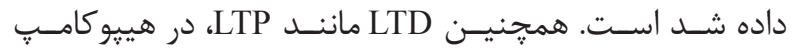

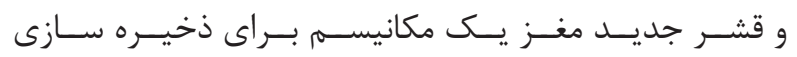

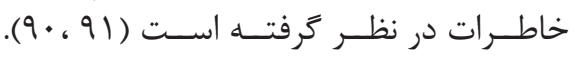

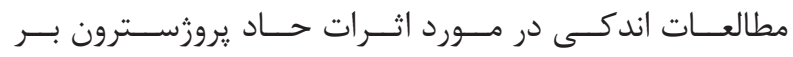

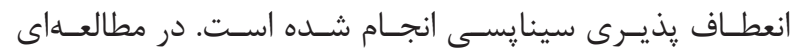

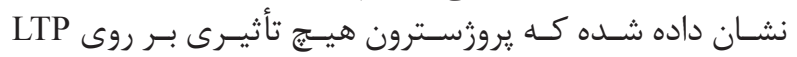

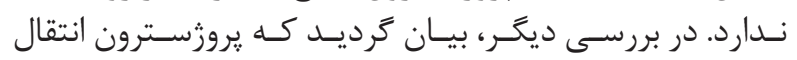

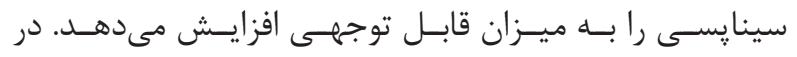

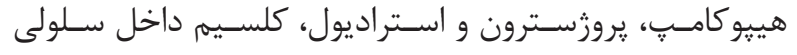

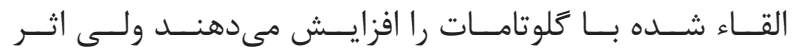

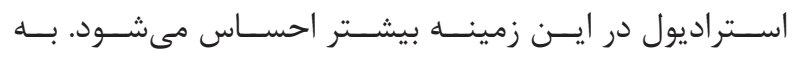

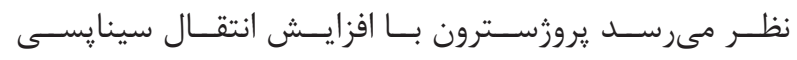

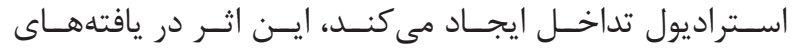

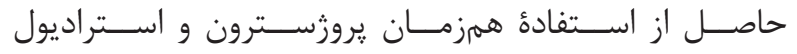

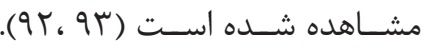

${ }^{29}$ Glial fibrillary acidic protein

${ }^{30} \alpha$-amino-3-hydroxy-5-methyl-4-isoxazolepropionic acid

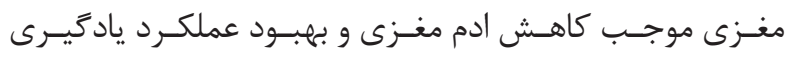

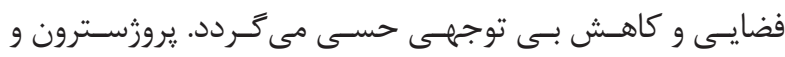

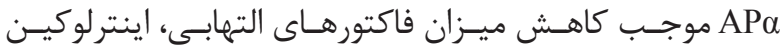

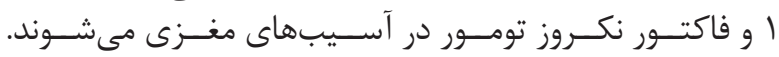

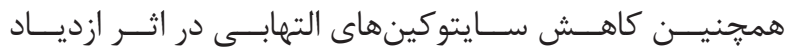

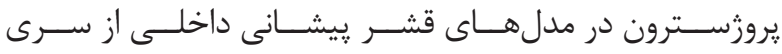

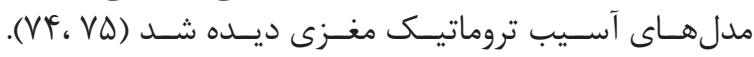

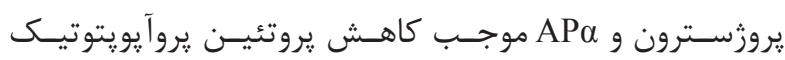

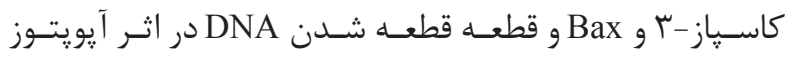

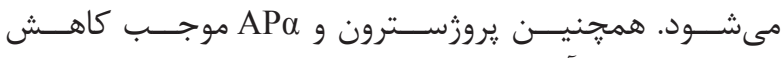

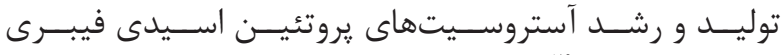

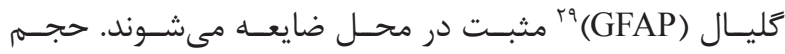

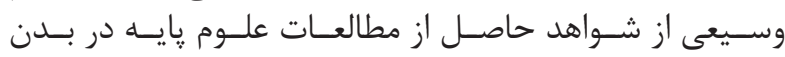

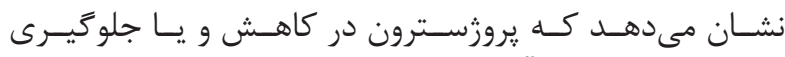

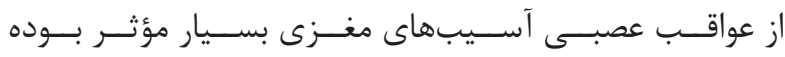
اسـت (V9، VV)

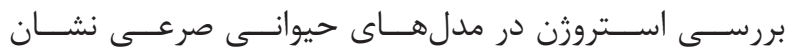

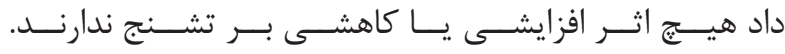

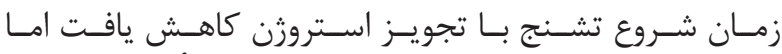

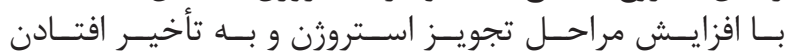

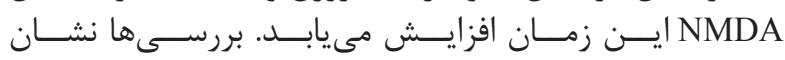

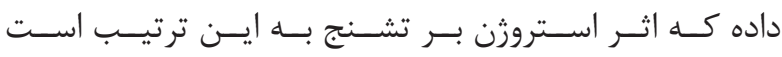

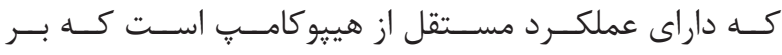

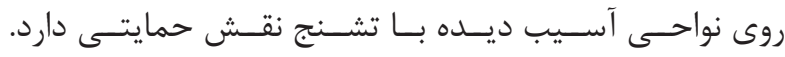

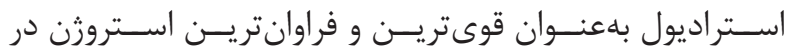

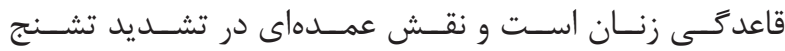

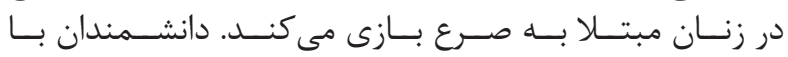

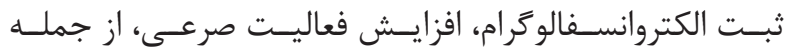

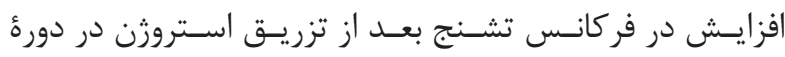

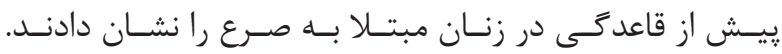

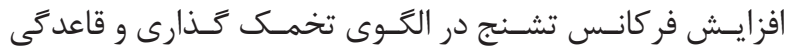

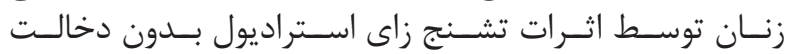

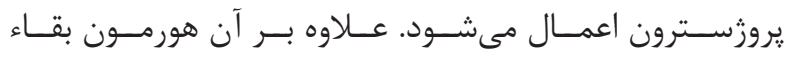

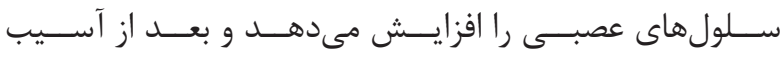

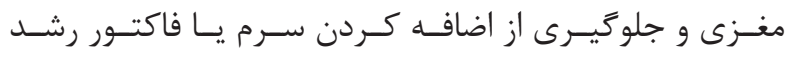

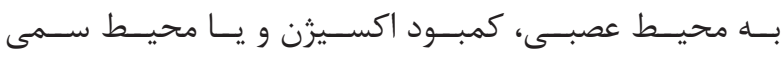

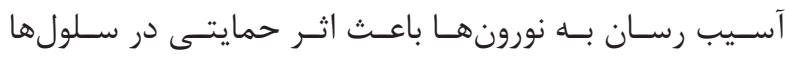

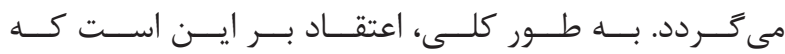

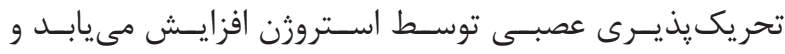

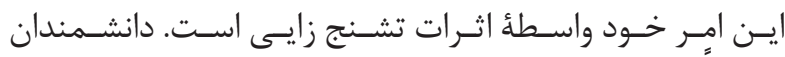

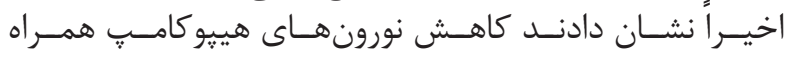

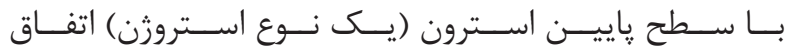

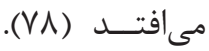

اثر هورمونهاى جنسى بر حافظه و يادَيرى

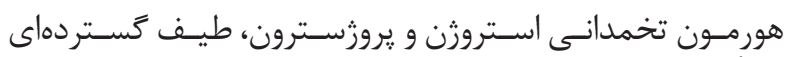

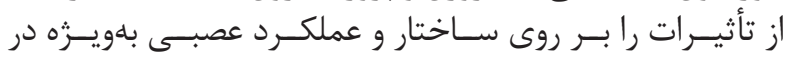

\footnotetext{
${ }^{31}$ Long term potentiation

${ }^{32}$ Long- term depression
} 


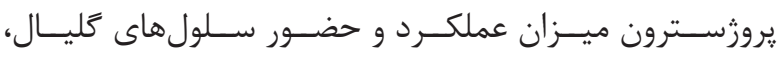

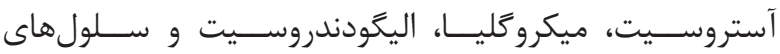
شـوان را تنظيـهم مى كنــد (99، (D9).

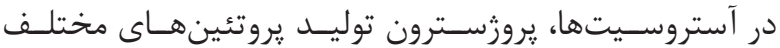

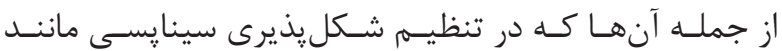

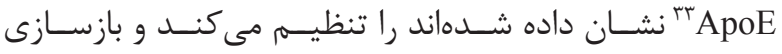

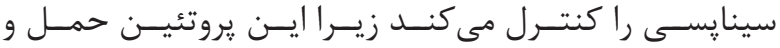

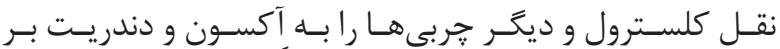

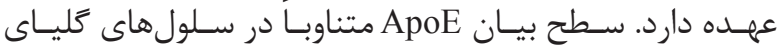

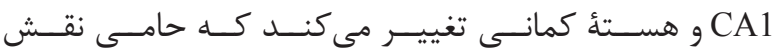

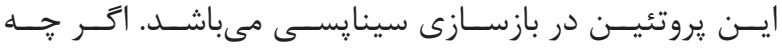

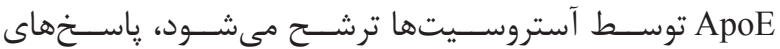

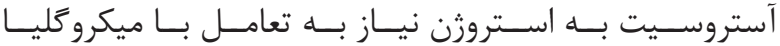

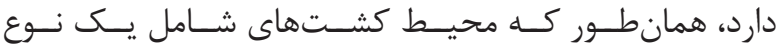

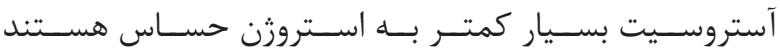

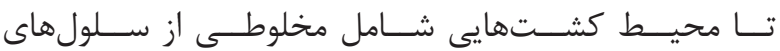

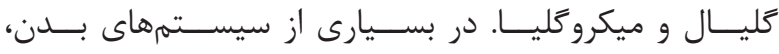

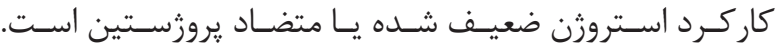

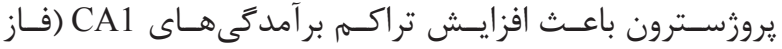

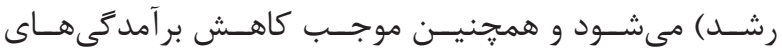

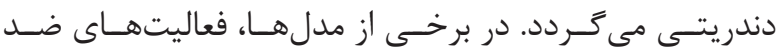

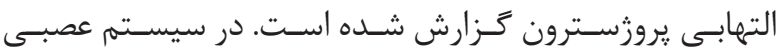

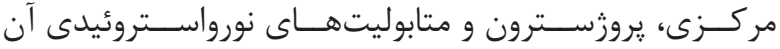

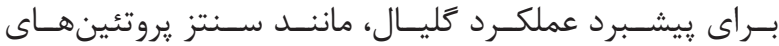

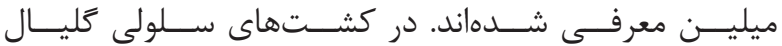

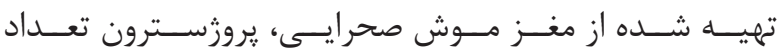

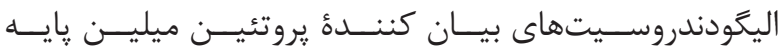

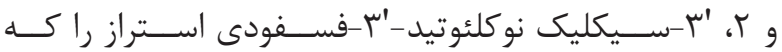

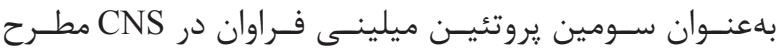

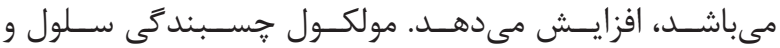

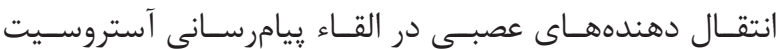

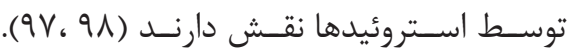

تأثير هورمونهاى جنسى بر تكثير سلولهاى عصبى

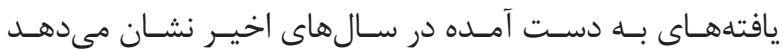

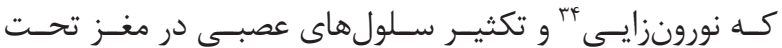

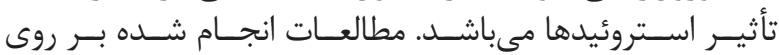

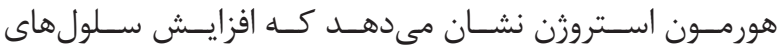

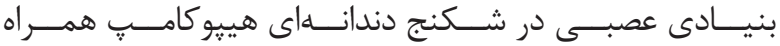

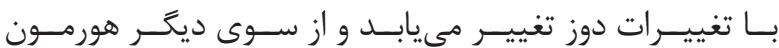

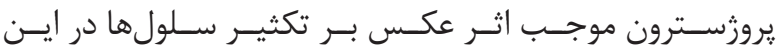

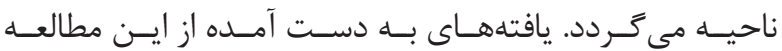

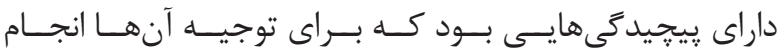

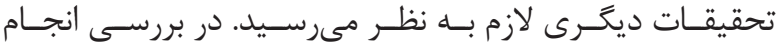

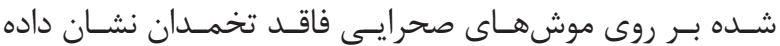

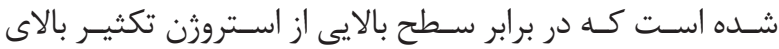

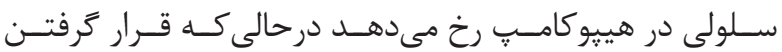

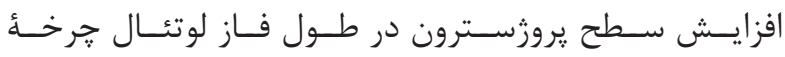

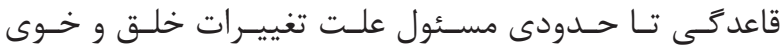

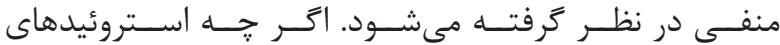

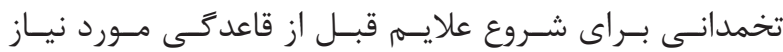

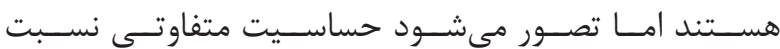

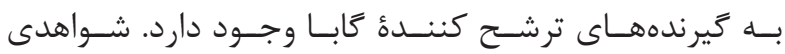

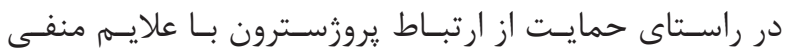

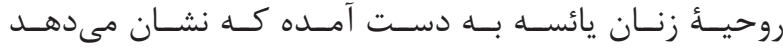

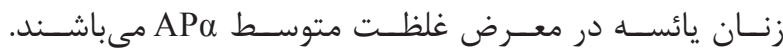

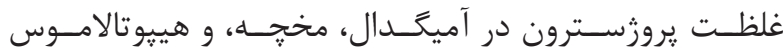

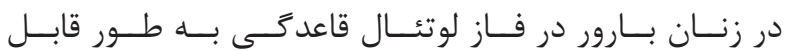

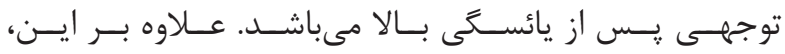

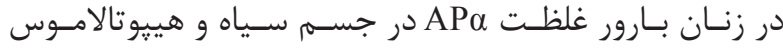

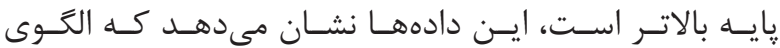

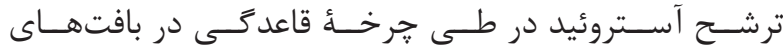

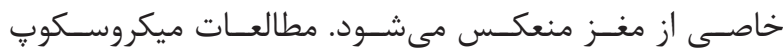

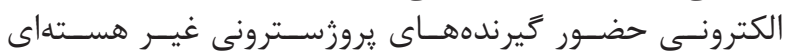

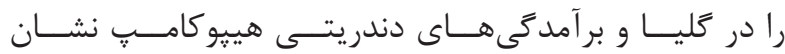

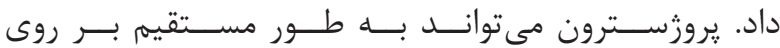

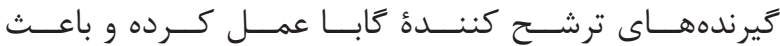

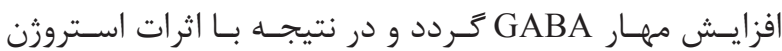

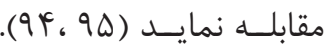

تأثير هورمونهاى جنسى بر تكثير سلول هاى غير عصبى

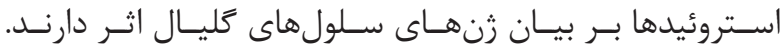

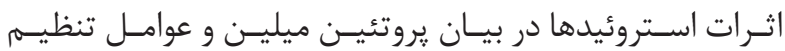

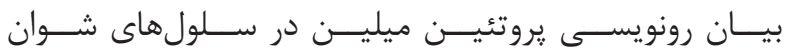

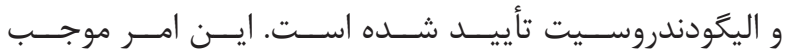

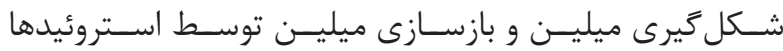

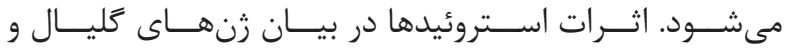

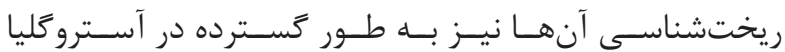

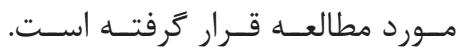

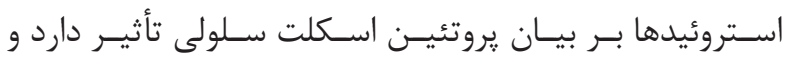

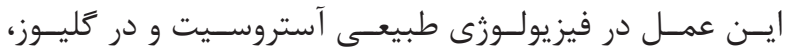

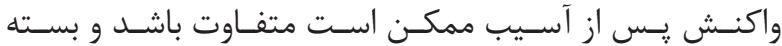

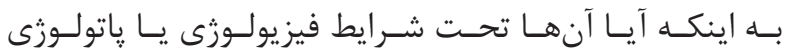

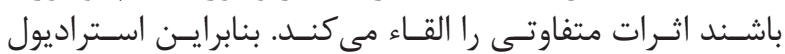

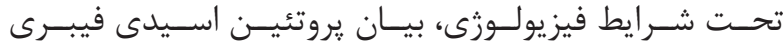

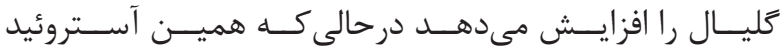

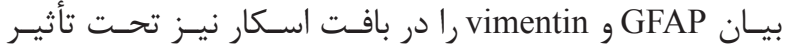

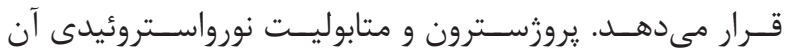

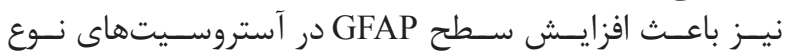

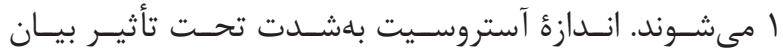

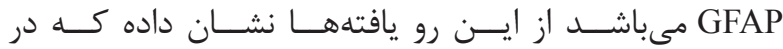

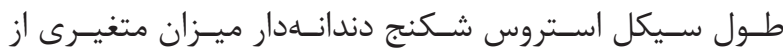

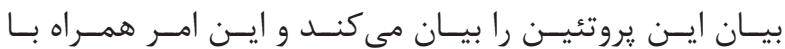

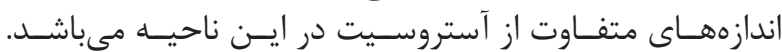

\footnotetext{
${ }^{33}$ Apolipoprotein E

${ }^{34}$ Neurogenesis
} 


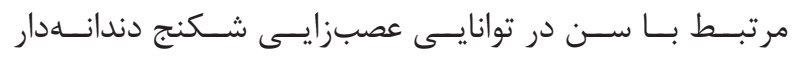

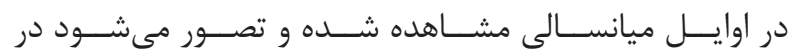

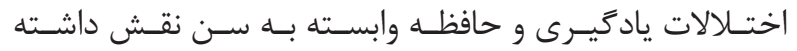

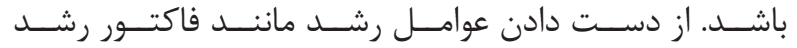

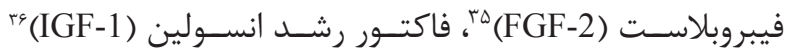

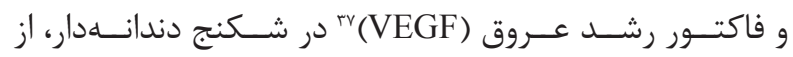

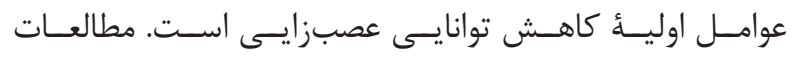

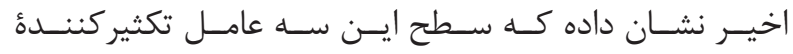

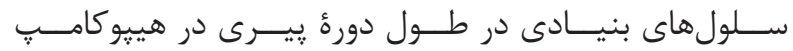

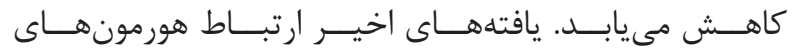

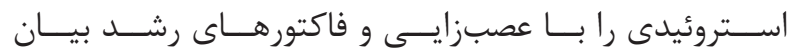

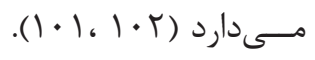
نتيجه

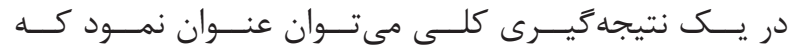

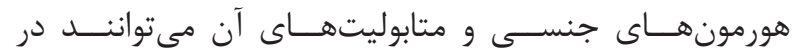

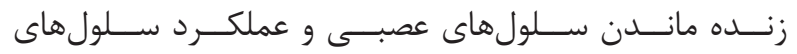

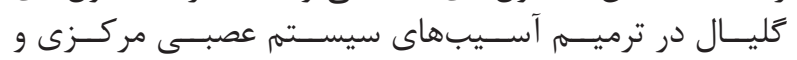

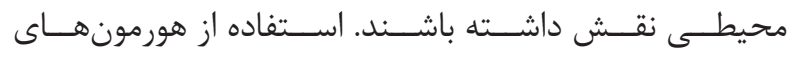

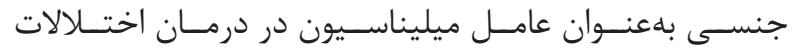

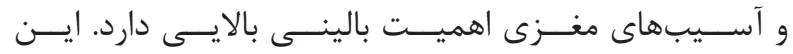

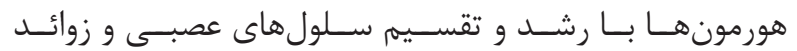

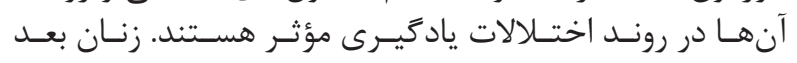

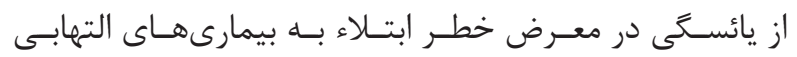

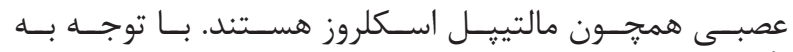

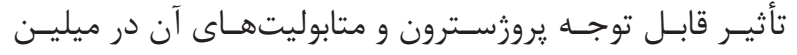

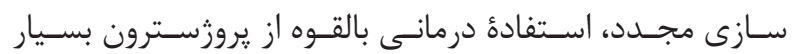

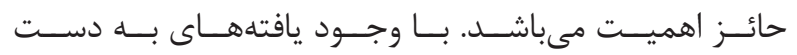

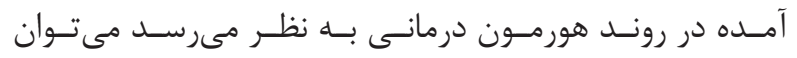

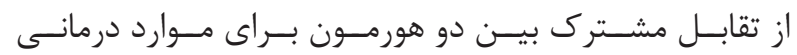

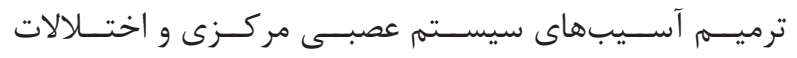
شــناختى اسـتفاده نمـود.

1. Gibbs RB. Long-term treatment with estrogen and progesterone enhances acquisition of a spatial memory task by ovariectomized aged rats. Neurobiology Aging. 2000; 21(1): 107-16.

2. Hoffmann S, Beyer C. Gonadal steroid hormones as therapeutic tools for brain trauma:the time is ripe for more courageous clinical trials to get into emergency medicine. J Steroid Biochem Mol Biol. 2015; 146: 1-2.

3. Gaignard P, Savouroux S, Liere P, Pianos A, Thérond $\mathrm{P}$, Schumacher M, et al. Effect of sex differences on brain mitochondrial function and its suppression by ovariectomy and in aged mice. Endocrinology. 2015; 156(8): 2893-904.

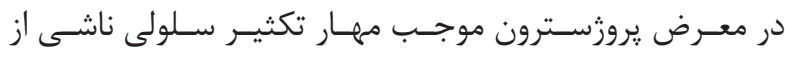

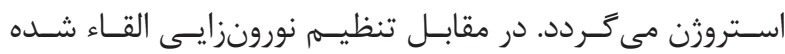

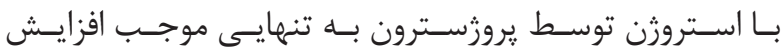

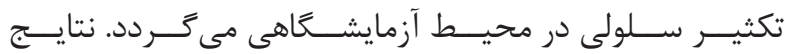

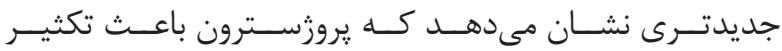

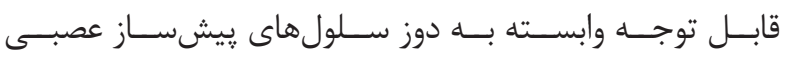
مىشـود (99).

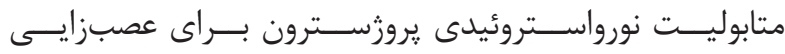

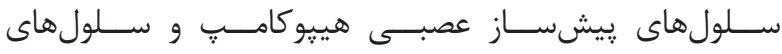

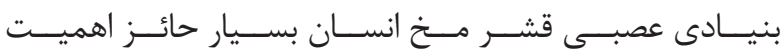

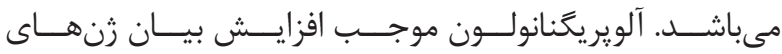

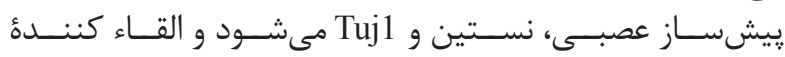

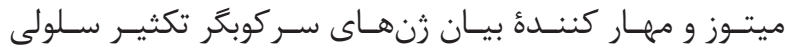

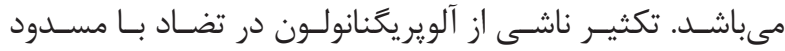

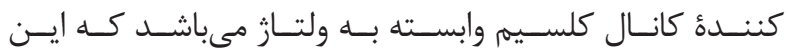

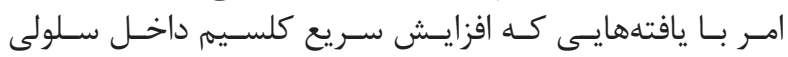

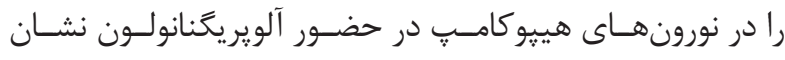

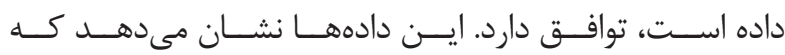

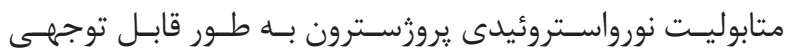

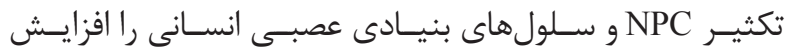

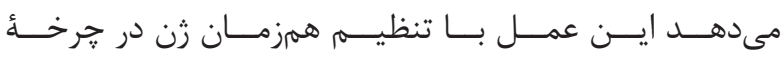

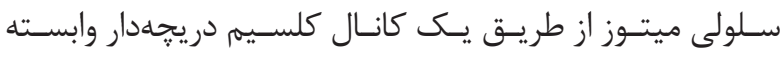

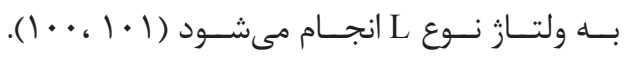

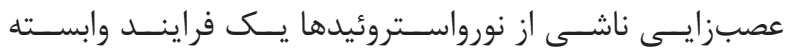

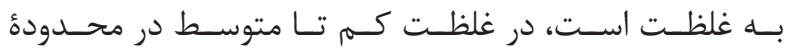

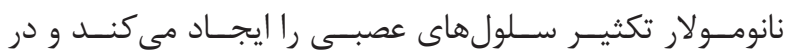

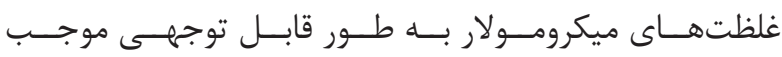

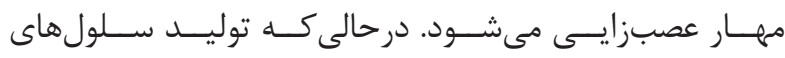

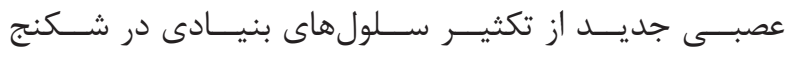

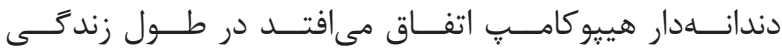

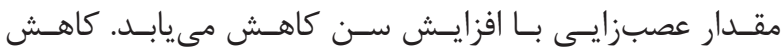

$$
\text { منابع }
$$

4. Brinton RD, Thompson RF, Foy MR, Baudry M, Wang J, Finch CE, et al. Progesterone receptors: form and function in brain. Neuroendocrinol. 2008; 29(2): $313-39$.

5. L Lammerding, A Slowik, S Johann, C Beyer. Poststroke inflammasome expression and regulation in the peri-infarct area by gonadal steroids after transient focal ischemia in the rat brain. Neuroendocrinology. 2016; 103(5): 460-75.

6. Guadalupe T, Zwiersc M, Wittfeld K, Teumere A, Vasquez A, Hoogman M, et al. Asymmetry within and around the human planum temporale is sexually dimorphic and influenced by genes involved in steroid

\footnotetext{
${ }^{35}$ Fibroblast growth factor

${ }^{36}$ Insulin-like growth factor-1

${ }^{37}$ Vascular endothelial growth factor
} 


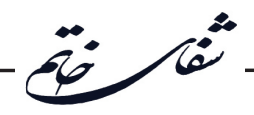

hormone receptor activity. Cortex. 2015; 62: 41-55.

7. Buimer MG, Wobbes T, Klinkenbijl JH, Reijnen MM, Blokx WA. Immunohistochemical analysis of steroid hormone receptors in hidradenitis suppurativa. Am J Dermatopathol. 2015; 37(2): 129-32.

8. Proctor WR, Diao L, Freund RK, Browning MD, Wu PH. Synaptic GABAergic and glutamatergic mechanisms underlying alcohol sensitivity in mousehippocampal neurons. J Physiol. 2006; 575(1): 145-59.

9. Manavathi B, Dey O, Gajulapalli VN, Bhatia RS, Bugide S, Kumar R. Derailed estrogen signaling and breast cancer: an authentic couple. Endocr Rev. 2013; 34(1): 1-32.

10. Nilsen J, Chen S, Brinton RD. Dual action of estrogen on glutamate-induced calcium signaling: mechanisms requiring interaction between estrogen receptors and src/ mitogen activated protein kinase pathway. Brain Res. 2002; 930(1-2): 216-34.

11. Akwa Y, Sananes N, Gouezou M, Robel P, Baulieu EE, Le Goascogne C. Astrocytes and neurosteroids: metabolism of pregnenolone and dehydroepiandrosterone regulation by cell density. J Cell Biol. 1993; 121(1): 135-43.

12. Ali A, Pillai KK, Vohora D. Evidence of the antiepileptic potential of amiloride with neuropharmacological benefits in rodent models of epilepsy and behaviour. Epilepsy Behav. 2004; 5(3): $322-8$.

13. Allport VC, Pieber D, Slater DM, Newton R, White JO, Bennett PR. Human labour is associated with nuclear factor-kB activity which mediates cyclooxygenase- 2 expression and is involved with the functional progesterone withdrawal. Mol Hum Reprod. 2001; 7(6): 581-6.

14. Leonelli E, Bianchi R, Cavaletti G, Caruso D, Crippa D, Garcia-Segura LM, et al. Progesterone and its derivatives are neuroprotective agents in experimental diabetic neuropathy: a multimodal analysis. Neuroscience. 2007; 144(4): 1293-304.

15. Allport VC, Slater DM, Newton R, Bennett PR. NF$\mathrm{kB}$ and AP-1 are required for cyclo-oxygenase 2 gene xpression in amnion epithelial cell line (WISH). Mol Hum Reprod. 2000; 6(6): 561-5.

16. Attali G, Weizman A, Gil-Ad I. Opposite modulatory effects of ovarian hormones on rat brain dopamine and serotonin transporters. Brain Res. 1997; 756(12): 153-9.

17. Magnaghi V, Veiga S, Ballabio M, Gonzalez LC,
Garcia-Segura LM, Melcangi RC. Sex-dimorphic effects of progesterone and its reduced metabolites on gene expression of myelin proteins by rat Schwann cells. J Peripher Nerv Syst. 2006; 11(2): 111-8.

18. Backstrom T. Epileptic seizures in women related to plasma estrogen and progesterone during the menstrual cycle. Acta Neurol Scand. 1976; 54(4): 321-47.

19. Pang Y, Dong J, Thomas P. Characterization, neurosteroid binding and brain distribution of human membrane progesterone receptors delta and \{epsilon\} (mPRdelta and mPR \{epsilon\}) and mPRdelta involvement in neurosteroid inhibition of apoptosis. Endocrinology. 2013; 154(1): 283-95.

20. Meffre D, Labombarda F, Delespierre B, Chastre A, De Nicola AF, Stein DG, et al. Distribution of membrane progesterone receptor alpha in the male mouse and rat brain and its regulation after traumatic brain injury. Neuroscience. 2013; 231: 111-24.

21. Backstrom T, Zetterlund B, Blom S, Romano M. Effect of intravenous progesterone infusions on the epileptic discharge frequency in women with partial epilepsy. Acta Neurol Scand. 1984; 69(4): 240-8.

22. Nourzad Z, Ghadiri T, Modarres Mousavi M, Karimzadeh F, Eshaghabadi A, Hosseini Ravandi H, et al. effect of concomitant use of erythropoietin and progesterone in traumatic brain injury. Shefaye Khatam. 2014; 2(3): 136.

23. Barha CK, Galea LA. Influence of different estrogens on neuroplasticity and cognition in the hippocampus. Biochim Biophys Acta. 2010; 1800(10): 1056-67.

24. Acharya KD, Finkelstein SD, Bless EP, Nettles SA, Mulac-Jericevic B, Conneely OM, et al. Estradiol Preferentially Induces Progestin Receptor-A (PR-A) Over PR-B in Cells Expressing Nuclear Receptor CoactivatorsintheFemaleMouseHypothalamus. eNeuro. 2015; 2(4): doi: 10.1523/ENEURO.0012-15.2015.

25. Arevalo MA, Azcoitia I, Garcia-Segura LM. The neuroprotective actions of oestradiol and oestrogen receptors. Nat Rev Neurosci. 2015; 16(1): 17-29.

26. Schumacher M, Mattern C, Ghoumari A, Oudinet JP, Liere P, Labombarda F,et al. Revisiting the roles of progesterone and allopregnanolone in the nervous system: resurgence of the progesterone receptors. Prog Neurobiol. 2014; 113: 6-39.

27. Thomas P, Pang Y. Membrane progesterone receptors: evidence for neuroprotective, neurosteroid signaling and neuroendocrine functions in neuronal 
cells. Neuroendocrinology. 2012; 96(2): 162-71.

28. Su C, Cunningham RL, Rybalchenko N, Singh M. Progesterone increases the release of brain-derived neurotrophic factor from glia via progesterone receptor membrane component 1 (Pgrmc1)-dependent ERK5 signaling. Endocrinology. 2012; 153(9): 4389-400.

29. Ishihara $Y$, Kawami T, Ishida A, Yamazaki T. Allopregnanolone-mediated protective effects of progesterone on tributyltin-induced neuronal injury in rat hippocampal slices. J Steroid Biochem Mol Biol. 2013; 135: 1-6.

30. Hughes GC, Clark EA, Wong AH. The intracellular progesterone receptor regulates $\mathrm{CD} 4+\mathrm{T}$ cells and $\mathrm{T}$ cell-dependent antibody responses. J Leukoc Biol. 2013; 93(3): 369-75.

31. Leonhardt SA, Boonyaratanakornkit V, Edwards DP. Progesterone receptor transcription and nontranscription signaling mechanisms. Steroids. 2003; 68(10-13): 761-70.

32. Conneely OM, Maxwell BL, Toft DO, Schrader WT, O'Malley BW. The A and B forms of the chicken progesterone receptor arise by alternate initiation of translation of a unique mRNA. Biochem Biophys Res Commun. 1987; 149(2): 493-501.

33. Obr AE, Edwards DP. The biology of progesterone receptor in the normal mammary gland and in breast cancer. Mol Cell Endocrinol. 2012; 357(1-2): 4-17.

34. Allan GF, Tsai SY, Tsai MJ, O’Malley BW. Liganddependent conformational changes in the progesterone receptor are necessary for events that follow DNA binding. Proc Natl Acad Sci U S A. 1992; 89(24): 11750-4.

35. Marshburn PB, Zhang J, Bahrani-Mostafavi Z, Matthews ML, White J, Hurst BS. Variant progesterone receptor mRNAs are co-expressed with the wild-type progesterone receptor mRNA in human endometrium during all phases of the menstrual cycle. Mol Hum Reprod. 2005; 11(11): 809-15.

36. Yousuf S, Atif F, Sayeed I, Tang H, Stein DG. Progesterone in transient ischemic stroke: a doseresponse study. Psychopharmacology (Berl). 2014; 231(17): 3313-23.

37. Mohammadzadeh E, Sahab Negah S, Eshaghabadi A. progesterone act as neuroprotective in traumatic brain injury. Shefaye Khatam. 2015; 3(3): 39.

38. Colangelo AM, Alberghina L, Papa M. Astrogliosis as a therapeutic target for neurodegenerative diseases.
Neurosci Lett. 2014; 565: 59-64.

39. Nourzad Z, Khazali H, Ghadiri T, Modarres Mousavi M, KarimzadehF, Eshaghabadi A, et al. Neuroprotective effects of concomitant use of erythropoietin and progesterone in traumatic brain injury. Shefaye Khatam. 2014; 2(2): 1-12.

40. Burda JE, Sofroniew MV. Reactive gliosis and the multicellular response to CNS damage and disease. Neuron. 2014; 81(2): 229-48.

41. Luis M, Roberto C.Steroids and glial cell function. Glia. 2006; 10: 485-98.

42. Enmark E, Pelto-Huikko M, Grandien K, Lagercrantz S, Lagercrantz J, Fried G, et al. Human estrogen receptor $\beta$ - gene structure, chromosomal localisation and expression pattern. J Clin Endocrinol Metab. 1997; 82(12): 4258-65.

43. Sherrington R, Rogaev EI, Liang Y, Rogaeva EA, Levesque $\mathrm{G}$, Ikeda $\mathrm{M}$, et al. Cloning of a gene bearing missense mutations in early onset familiar Alzheimer's disease. Nature. 1995; 375(6534): 754-60.

44. Mosselman S, Pohlman J, Dijkema R. ER $\beta$ identification and characterisation of a novel human estrogen receptor. FEBS Lett. 1996; 392(1): 49-53.

45. Mani SK, Mermelstein PG, Tetel MJ, Anesetti G. Convergence of multiple mechanisms of steroid hormone action. Horm Metab Res. 2012; 44(8): 569-76.

46. Lakaye B, Foidart A, Grisar T, Balthazart J.Partial cloning and distribution of estrogen receptor beta in the avian brain. Neuroreport. 1998; 9(12): 2743-48.

47. Todo T, Adachi S, Yamauchi K. Molecular cloning and characterization of Japanese eel estrogen receptor cDNA. Mol Cell Endocrinol. 1996; 119: 37-45.

48. Brzozowski AM, Pike Acw, Dauter Z. Molecular basis of agonism and antagonism in the oestrogen receptor. Nature. 1997; 389(6652): 753-9.

49. Trabert B, Wentzensen N, Yang HP, Sherman ME, Hollenbeck AR, Park Y, et al. Is estrogen plus progestin menopausal hormone therapy safe with respect to endometrial cancer risk? Int J Cancer. 2013; 132(2): 417-26.

50. Klein-Nulend J, van Oers RF, Bakker AD, Bacabac RG. Bone cell mechanosensitivity, estrogen deficiency, and osteoporosis. J Biomech. 2015; 48(5): 855-65.

51. Chen P, Wang H, Duan Z, Zou JX Chen H, He W, et 


\section{0}

al. Estrogen-related receptor alpha confers methotrexate resistance via attenuation of reactive oxygen species production and P53 mediated apoptosis in osteosarcoma cells. Biomed Res Int. 2014; 2014: 616025. doi: 10.1155/2014/616025.

52. Witkowska HE, Carlquist M, Engstrom O.Characterization of bacterially expressed rat estrogen receptor beta ligand binding domain by mass spectrometry: structural comparison with estrogen receptor alpha. Steroids. 1997; 62(8-9): 621-31.

53. Kuiper GG, Lemmen JG, Carlsson B, Corton JC, Safe SH, van der Saag PT, et al. Interaction of estrogenic chemicals and phytoestrogens with estrogen receptor $\beta$. Endocrinology. 1998; 139(10): 4252-63.

54. Jobling S, Reynolds $\mathrm{T}$, White R, Parker MG, Sumpter JP.A variety of environmentally persistent chemicals, including some phtalate plasticizers, are weakly estrogenic. Environ Health Perspectives. 1995; 103(6): $\quad 582-87$.

55. Goldin BR, Gorbach SL, Hockerstedt KA. Soybean phytoestrogen intake and cancer risk. J Nutrition. 1995; 125(3): 757-70.

56. Fisher CR, Graves KH, Parlow AF. Simpson ER.Characterisation of mice deficient in aromatase (ArKO) because of targeted disruption of the cyp19 gene. Proc Natl Acad Sci USA. 1998; 95(12): 6965-70.

57. Ogawa S, Taylor JA, Lubahn DB, Korach KS, Pfaff DW. Reversal of sex roles in genetic females by disruption of estrogen receptor gene. Neuroendocrinology. 1996; 64(6): 467-70.

58. Bocchinfuso WP, Korach KS. Biological impact of a disrupted estrogen receptor gene on estrogen-related cancer. Endocrine Related Cancer. 1997; 4: 387-406.

59. Korach KS, Couse JF, Curtis SW. Estrogen receptor gene disruption: molecular characterization and experimental and clinical phenotypes. Recent Prog Hormone Res. 1996; 51: 159-88.

60. Zhou Y, Watters JJ, Dorsa DM. Estrogen rapidly induces the phosphorylation of the cAMP response element binding protein in rat brain. Endocrinology. 1996; 137(5): 2163-6.

61. Nilsen J, Irwin RW, Gallaher TK, Brinton RD. Estradiol in vivo regulation of brain mitochondrial proteome. J Neurosci. 2007; 27(51): 14069-77.

62. Labombarda F, Ghoumari AM, Liere P, De Nicola AF, Schumacher M, Guennoun R. Neuroprotection by steroids after neurotrauma in organotypic spinal cord cultures: a key role for progesterone receptors and steroidal modulators of $\mathrm{GABA}(\mathrm{A})$ receptors. Neuropharmacology. 2013; 71: 46-55.

63. Backstrom T, Haage D, Lofgren M, Johansson IM, Stromberg J, Nyberg S, et al. Paradoxical effects of GABA-A modulators may explain sex steroid induced negative mood symptoms in some persons. Neuroscience. 2011; 191: 46-54.

64. Bethea CL, Reddy AP. Ovarian steroids increase glutamatergic related gene expression in serotonin neurons of macaques. Mol Cell Neurosci. 2012; 49(3): 251-62.

65. Wang J, Green PS, Simpkins JW. Estradiol protects against ATP depletion, mitochondrial membrane potential decline and the generation of reactive oxygen species induced by 3-nitroproprionic acid in SK-N-SH human neuroblastoma cells. J Neurochem. 2001; 77(3): 804-11.

66. Beyenburg S, Stoffel-Wagner B, Bauer J, Watzka M, Blumcke I, Bidlingmaier F, et al. Neuroactive steroids and seizure susceptibility. Epilepsy Res. 2001; 44(2-3): 141-53.

67. Nin MS, Martinez LA, Pibiri F, Nelson M, Pinna G. Neurosteroids reduce social isolation-induced behavioral deficits: a proposed link with neurosteroidmediated upregulation of BDNF expression. Front Endocrinol (Lausanne). 2011; 2: 73. doi: 10.3389/ fendo.2011.00073.

68. Pang Y, Thomas P. Progesterone signals through membrane progesterone receptors (mPRs) in MDAMB-468 and mPR-transfected MDA-MB-231 breast cancer cells which lack full-length and N-terminally truncated isoforms of the nuclear progesterone receptor. Steroids. 2011; 76(9): 921-8.

69. Frye CA, Scalise TJ. Anti-seizure effects of progesterone and 3alpha,5alpha-THP in kainic acid and perforant pathway models of epilepsy. Psychoneuroendocrinology. 2000; 25(4): 407-20.

70. Frye CA, Bayon LE. Seizure activity is increased in endocrine states characterized by decline in endogenous levels of the neurosteroid 3 alpha,5 alpha-THP. Neuroendocrinology. 1998; 68(4): 272-80.

71. Haan N, Zhu B, Wang J, Wei X, Song B. Crosstalk between macrophages and astrocytes affects proliferation, reactive phenotype and inflammatory response, suggesting a role during reactive gliosis following spinal cord injury. J Neuroinflammation. 2015; 12: 109. doi: 10.1186/s12974-015-0327-3.

72. Geddes RI, Sribnick EA, Sayeed I, Stein DG. 
Progesterone treatment shows benefit in a pediatric model of moderate to severe bilateral brain injury. PLoS One. 2014; 9(1): e87252.

73. Liu F, Liao F, Li W, Han Y, Liao D. Progesterone alters Nogo-a, GFAP and GAP-43 expression in a rat model of traumatic brain injury. Mol Med Rep. 2014; 9(4): 1225-31.

74. Borras C, Sastre J, Garcia-Sala D, Lloret A, Pallardo FV, Vina J. Mitochondria from females exhibit higher antioxidant gene expression and lower oxidative damage than males. Free Radic Biol Med. 2003; 34(5): 546-52.

75. Robertson CL, Puskar A, Hoffman GE, Murphy AZ, Saraswati M, Fiskum G. Physiologic progesterone reduces mitochondrial dysfunction and hippocampal cell loss after traumatic brain injury in female rats. Exp Neurol. 2006; 197(1): 235-43.

76. Wade CB, Dorsa DM. Estrogen activation of cyclic adenosine 5'-monophosphate response elementmediated transcription requires the extracellularly regulated kinase/mitogen-activated protein kinase pathway. Endocrinology. 2003; 144: 832-8.

77. Tang H, Hua F, Wang J, Sayeed I, Wang X, Chen Z, et al. Progesterone and vitamin D: improvement after traumatic brain injury in middle-aged rats. Horm Behav. 2013; 64(3): 527-38.

78. Daubner SC, Le T, Wang S. Tyrosine hydroxylase and regulation of dopamine synthesis. Arch Biochem Biophys. 2011; 508(1): 1-12.

79. Frye CA. The neurosteroid 3 alpha, 5 apha-THP has antiseizure and possible neuroprotective effects in an animal model of epilepsy. Brain Res. 1995; 696(1-2): 113-20.

80. Gibson CL, Constantin D, Prior MJ, Bath PM, Murphy SP. Progesterone suppresses the inflammatory response and nitric oxide synthase-2 expression following cerebral ischemia. Exp Neurol. 2005; 193(2): 522-30.

81. Wong M, Moss RL. Electrophysiological evidence for a rapid membrane action of the gonadal steroid, 17b-estradiol, on CA1 pyramidal neurons of the rat hippocampus. Brain Research Bulletin. 1991; 543: 148-52.

82. Ito M. The cerebellum and neural control. New York: Raven Press. 1984.

83. Bear MF, Malenka RC. Synaptic plasticity: LTP and LTD. Current Opinion in Neurobiology. 1994; 4(3):
389-99.

84. Dudek SM, Bear MF. Homosynaptic long-term depression in area CA1 of hippocampus and effects of N-methyl-D-aspartate receptor blockade. Proc Natl Acad Sci U S A. 1992; 89(10): 4363-7.

85. Shors TJ, Matzel LD. Long-term potentiation: what's learning got to do with it? Behav Brain Sci. 1997; 20(4): 597-614.

86. Bi GQ, Poo MM. Synaptic modification by correlated activity: Hebb's postulate revisited. Annu Rev Neurosci. 2001; 24: 139-66.

87. Grover LM, Teyler TJ. Two components of longterm potentiation induced by different patterns of afferent activation. Nature. 1990; 347(6292): 477-9.

88. Backstrom T, Sanders D, Leask R, Davidson D, Warner P, Bancroft J. Mood, sexuality, hormones, and the menstrual cycle. II. Hormone levels and their relationship to the premenstrual syndrome. Psychosom Med. 1983; 45(6): 503-7.

89. Klintsova A, Levy WB, Desmond NL. Astrocytic volume fluctuates in the hippocampal CA1 region across the estrous cycle. Brain Res. 1995; 690(2): 269-74.

90. Cashion AB, Smith MJ, Wise PM. The morphometry of astrocytes in the rostral preoptic area exhibits a diurnal rhythm on proestrus: relationship to the luteinizing hormone surge and effects of age. Endocrinology. 2003; 144(1): 274-80.

91. Stone DJ, Song Y, Anderson CP, Krohn KK, Finch $\mathrm{CE}$, Rozovsky I. Bidirectional transcription regulation of glial fibrillary acidic protein by estradiol in vivo and in vitro. Endocrinology. 1998; 139(7): 3202-9.

92. Giachino C, Galbiati M, Fasolo A, Peretto P, Melcangi RC. Effects of progesterone derivatives, dihydroprogesterone and tetrahydroprogesterone, on the subependymal layer of the adult rat. J Neurobiol. 2004; 58(4): 493-502.

93. Sayeed I, Parvez S, Wali B, Siemen D, Stein DG. Direct inhibition of the mitochondrial permeability transition pore: a possible mechanism for better neuroprotective effects of allopregnanolone over progesterone. Brain Res. 2009; 1263: 165-73.

94. Azcoitia I, Yague JG, Garcia-Segura LM. Estradiol synthesis within the human brain. Neuroscience. 2011; 191: 139-47.

95. Mahley RW, Rall SC Jr. Apolipoprotein E: far more 
than a lipid transport protein. Annu Rev Genomics Hum Genet. 2000; 1: 507-37.

96. Stone DJ, Rozovsky I, Morgan TE, Anderson CP, Hajian H, Finch CE. Astrocytes and microglia respond to estrogen with increased apoE mRNA in vivo and in vitro. Exp Neurol. 1997; 143(2): 313-8.

97. Nathan BP, Barsukova AG, Shen F, McAsey M, Struble RG. Estrogen facilitates neurite extension via apolipoprotein $\mathrm{E}$ in cultured adult mouse cortical neurons. Endocrinology. 2004; 145(7): 3065-73.

98. Graham JD, Clarke CL. Physiological action of progesterone in target tissues. Endocr Rev. 1997; 18(4): 502-19.

99. Tanapat P, Hastings NB, Gould E. Ovarian steroids influence cell proliferation in the dentate gyrus of the adult female rat in a dose- and time-dependent manner. $\mathrm{J}$ Comp Neurol. 2004; 481(3): 252-65.

100. Gage FH. Neurogenesis in the adult brain. J Neurosci. 2002; 22: 612-3.

101. Kuhn HG, Dickinson-Anson H, Gage FH. Neurogenesis in the dentate gyrus of the adult rat: agerelated decrease of neuronal progenitor proliferation. J Neurosci. 1996; 16(6): 2027-33.

102. Rao MS, Hattiangady B, Abdel-Rahman A, Stanley DP, Shetty AK. Newly born cells in the ageing dentate gyrus display normal migration, survival and neuronal fate choice but endure retarded early maturation. Eur J Neurosci. 2005; 21(2): 464-76. 